\title{
State analysis using the Local Ensemble Transform Kalman Filter (LETKF) and the three-layer circulation structure of the Luzon Strait and the South China Sea
}

\author{
Fang-Hua Xu • Lie-Yauw Oey
}

Received: 30 September 2013 / Accepted: 14 April 2014 / Published online: 29 May 2014

(C) The Author(s) 2014. This article is published with open access at Springerlink.com

\begin{abstract}
A new circulation model of the western North Pacific Ocean based on the parallelized version of the Princeton Ocean Model and incorporating the Local Ensemble Transform Kalman Filter (LETKF) data assimilation scheme has been developed. The new model assimilates satellite data and is tested for the period January 1 to April 3, 2012 initialized from a 24-year simulation to estimate the ocean state focusing in the South China Sea (SCS). Model results are compared against estimates based on the optimum interpolation (OI) assimilation scheme and are validated against independent Argo float and transport data to assess model skills. LETKF provides improved estimates of the western North Pacific Ocean state including transports through various straits in the SCS. In the Luzon Strait, the model confirms, for the first time, the three-layer transport structure previously deduced in the literature from sparse observations: westward in the upper and lower layers and eastward in the middle layer. This structure is shown to be robust, and the related dynamics are analyzed using the results of a long-term (18 years) unassimilated North Pacific Ocean model. Potential vorticity and mass conservations suggest a
\end{abstract}

Responsible Editor: Yasumasa Miyazawa

This article is part of the Topical Collection on the 5 th International Workshop on Modelling the Ocean (IWMO) in Bergen, Norway 17-20 June 2013

F.-H. Xu $(\bowtie)$

Ministry of Education Key Laboratory for Earth System Modeling,

Center for Earth System Science, Tsinghua University, Beijing,

China

e-mail: fxu@tsinghua.edu.cn

L.-Y. Oey

National Central University, Zhongli, Taiwan

L.-Y. Oey

Program in Atmospheric and Oceanic Sciences, Princeton

University, Princeton, USA basin-wide cyclonic circulation in the upper layer of the SCS $(z>-570 \mathrm{~m})$, an anticyclonic circulation in the middle layer $(-570 \mathrm{~m} \geq z>-2,000 \mathrm{~m})$, and, in the abyssal basin $(<$ $-2,000 \mathrm{~m})$, the circulation is cyclonic in the north and anticyclonic in the south. The cyclone-anticyclone abyssal circulation is confirmed and explained using a deep-layer reducedgravity model as being caused by overflow over the deep sill of the Luzon Strait, coupled with intense, localized upwelling west of the strait.

Keywords Three-layer circulation of South China Sea . Three-layer Luzon Strait transport · Local Ensemble Transform Kalman Filter (LETKF) · Data assimilation · Ocean modeling

\section{Introduction}

The western North Pacific Ocean and South China Sea (SCS) adjacent to the Asian continent play a significant role in regional and global weather and climate variability (e.g., $\mathrm{Hu}$ et al. 2000; Xie et al. 2003; Qu et al. 2004, 2006a, 2009; Xue et al. 2004; Gan et al. 2006; Wang et al. 2006; Gordon et al. 2012; Sprintall et al. 2012). South China Sea is among the world's biologically most diverse ecosystem which is threatened by economic developments and anthropogenic inputs (Liu 2013). Understanding and predicting the ocean circulation in that region are of interest for both scientific research and ecosystem management studies.

East of the Luzon Strait, the Kuroshio flows northnortheastward, and a branch of it intrudes into the SCS through the Luzon Strait. Northeast of Taiwan, a branch of the Kuroshio also enters the East China Sea (ECS; Isobe 2008). The Kuroshio waters modify the marginal seas' heat and salt fluxes, as well as biogeochemical balances (Liu et al. 2000). Monsoon winds, tides, and rivers have significant influences on the circulation and mixing of the marginal seas 
(Qu 2000; Guo et al. 2006; Isobe 2008). Warm and cold eddies affect heat and salt transports, the surface winds, and possibly also the intensity and spawning of typhoons (Oey et al. 2013).

Regional, high-resolution circulation models are useful for both understanding processes and providing practical services to the community, such as tracking pollutants, identification of fishing grounds, and for search and rescue. Recently, we have developed a comprehensive ocean prediction system - the Advanced Taiwan Ocean Prediction (ATOP) system (Oey et al. 2013). The ATOP system is now operational; once a day, it provides -7 -day analysis and +7 -day forecast for the North Pacific Ocean (http://mpipom.ihs.ncu.edu.tw) by assimilating satellite data using a simple statistical optimum interpolation (OI) scheme. This paper develops a western North Pacific regional model of ATOP and implements the Local Ensemble Transform Kalman Filter (LETKF; Hunt et al. 2007; see the extensive list of references in $\mathrm{Xu}$ et al. 2013a) scheme for data assimilation. LETKF has been successfully used in atmospheric studies, such as Szunoygh et al. (2005) and Miyoshi et al. (2010). The method has now been applied to the ocean. Miyazawa et al. (2012) implemented the LETKF algorithm into the parallelized version of the Princeton Ocean Model (POM; Jordi and Wang 2012) and showed that the method can simulate well the complex interactions between the Kuroshio and coastal seas south of Japan. Xu et al. (2013a) used LETKF to analyze the Loop Current and eddy variability in the Gulf of Mexico. For the SCS, a number of numerical models (e.g., Shaw and Chao 1994; Metzger and Hurlburt 1996, 2001; Chu et al. 1999; Xue et al. 2004; Gan et al. 2006; Hsin et al. 2012; Lan et al. 2013) have been developed to study its circulation. However, a dataassimilated analysis using LETKF in the SCS has not been previously attempted. The first goal of this study is therefore to produce and validate a test case of LETKF data-assimilated analysis for the western North Pacific Ocean focusing on the SCS and compare the results with the ATOP analysis using the OI scheme, as well as with observations.

The SCS is connected to the Pacific Ocean by the Luzon Strait which with a sill depth of $\sim 2,000 \mathrm{~m}$ is the only deep pathway between the two basins. The Kuroshio intrudes into SCS through the upper Luzon Strait, and deep water overflows from the denser Pacific to the relatively lighter SCS below about 1,500 m (Qu et al. 2006b). The structure of the middle layer remains unclear but water mass analysis suggests an outflow of SCS intermediate water (SCSIW) which may be traced to locations as far north as the Okinawa Trough (Chen and Wang 1998; Chen 2005). The mechanisms for the Kuroshio intrusion and the deep overflow have attracted considerable attention (e.g., Qu et al. 2006b). Further studies are still needed to understand the mechanisms. The upper layer circulations have been extensively studied by previous observation and modeling studies (e.g., Qu 2000; Gan et al. 2006; and references cited above). On the other hand, apart from a few studies (Wang et al. 2011; Lan et al. 2013), the intermediate and deep circulations have rarely been discussed. The second goal of this study is therefore to use LETKF analysis and the long-term results (1991-2008) of an unassimilated run (Oey et al. 2013) to quantitatively estimate the Luzon Strait transport (LST) and then, as a third goal, to explain the three-layer structure of LST and mean circulation of the SCS. To the best of our knowledge, this is the first time that the three-layer circulation structures of the Luzon Strait and SCS have been simulated in a model.

The paper is organized as follows. Section 2 describes the model and Section 3 LETKF. Section 4 compares LETKF and OI analysis results against observations and shows the existence of the three-layer flow structure in the Luzon Strait. Section 5 demonstrates the robustness of the three-layer structure using the long-term unassimilated model run and explains the corresponding basin-wide circulation in the SCS. Discussions and conclusions are given in Section 6.

\section{Regional North Pacific models}

We configure two ATOP models, as detailed in Oey et al. (2013). One ATOP model is configured for the western North Pacific Ocean (WPac) from $99^{\circ}$ to $131^{\circ} \mathrm{E}$ and $12^{\circ} \mathrm{S}$ to $42^{\circ} \mathrm{N}$ at approximately $0.1^{\circ} \times 0.1^{\circ}$ horizontal resolution and 31 vertical sigma levels (Fig. 1); it includes all the China seas. Another ATOP model for the entire North Pacific is referred to as "Pac10" which has a resolution of $0.1^{\circ} \times 0.1^{\circ}$ and 41 vertical sigma levels. The sigma cells are finer, logarithmically distributed near the free surface and bottom, so that the grid cell nearest the top (bottom) boundary is approximately $2 \sim 3 \mathrm{~m}$ below (above) the surface (bottom) in 1,000-m water depth, and the corresponding grid spacing in the middle of the water column is approximately $30 \sim 38 \mathrm{~m}$. The topography was set up according to the Etopo2. ATOP uses mpiPOM: the Message Passing Interface (mpi) version of the Princeton Ocean Model (Blumberg and Mellor 1987); Dr. Toni Jordi implemented MPIs into the model (Jordi and Wang 2012, http://www. imedea.uib-csic.es/users/toni/sbpom/index.php). The mpiPOM is an efficient parallel code and retains most of the original POM physics. It incorporates new features and modules from the Princeton Regional Ocean Forecast System (PROFS) (http://www.aos.princeton.edu/WWWPUBLIC/ PROFS/publications.html), such as wave-enhanced bottom drag, passive tracer, particle tracking, and stokes drift. The horizontal diffusion terms are rewritten (Mellor and Blumberg 1985) to eliminate artificial diapycnal diffusion while both surface and bottom boundary layers can be realistically modeled over sloping topography. A fourth-order scheme is 
Fig. 1 Western North Pacific model Ocean domain (from $99^{\circ} \mathrm{E}$ to $130^{\circ} \mathrm{E}$ and $11.5^{\circ} \mathrm{S}$ to $41.5^{\circ} \mathrm{S}$ ). Six transects in South China Sea (SCS) are marked (Taiwan Strait, Luzon Strait, Mindoro-Panay Strait, Balabac Strait, Sibutu Passage, and Karimata Strait; solid line). Two transects east of Taiwan $\left(22.9^{\circ} \mathrm{N}\right)$ and east of Luzon Island $\left(18^{\circ} \mathrm{N}\right)$ are also marked. Seven black diamonds indicate the Argo data locations. Gray lines are 50-, 500-, and 2,000-m isobaths

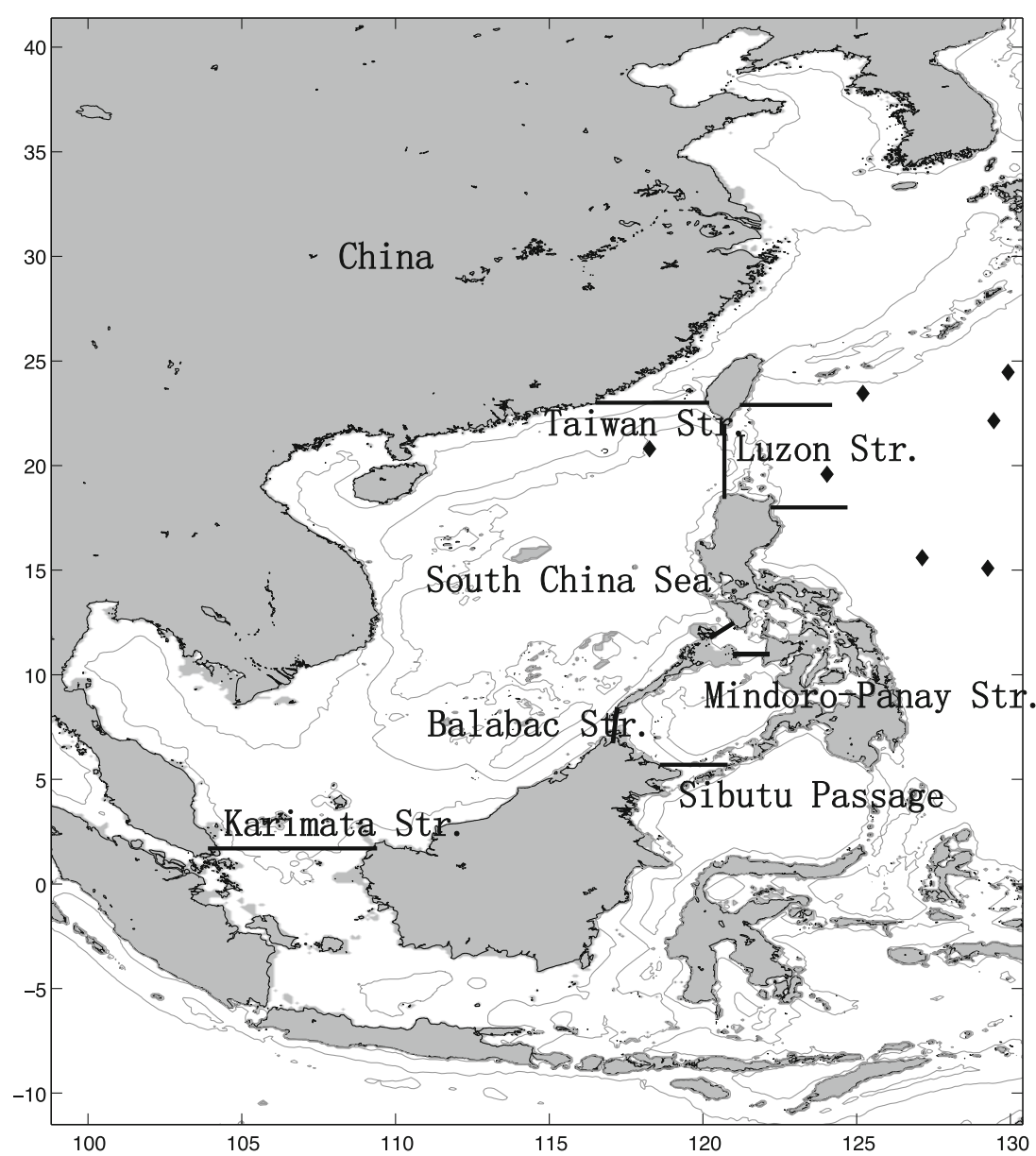

used to render the so-called sigma-level pressure gradient errors negligible (Berntsen and Oey 2010). Details of the ATOP configuration are described in Oey et al. (2013).

The WPac is forced by six-hourly NCEP $0.5^{\circ} \times 0.5^{\circ}$ Global Forecast System (GFS; http://nomads.ncdc.noaa.gov/data. php) wind. Boundary conditions are zero normal flux (of any kind) across solid boundaries. Along the open boundaries, World Ocean Atlas (WOA) climatological $T$ and $S$ from NODC (http://www.nodc.noaa.gov/OC5/WOA05/pr woa05.html) are specified within $1.5^{\circ}$-wide flow-relaxation zones (Oey and Chen 1992a, b). Transports across the open boundaries are specified from Pac10 together with the Flather radiation scheme (Oey and Chen 1992a, b). In this way, boundary transports consistent with large-scale (e.g., wind) forcing are retained, while the baroclinic velocity is consistent with the observed WOA climatology. At the sea surface, the sea surface temperature (SST) is relaxed to monthly WOA values using an e-folding time constant of $1 / 30 \mathrm{day}^{-1}$. The sea surface salinity (SSS) is similarly relaxed to climatological WOA values. The WPac uses OI method to assimilate AVISO (Archiving, Validation and Interpretation of Satellite Oceanographic data) satellite sea surface height anomaly (SSHA, http://www.aviso.oceanobs.com/) data. The optimally interpolated gridded, daily data provided by SSALTO/
DUACS on a $1 / 3^{\circ} \times 1 / 3^{\circ}$ Mercator grid is used. The SSHA data $(\eta)$ over water depth $<500 \mathrm{~m}$ is excluded since they tend to be less accurate near the coasts. The gridded SSHA data was projected to the subsurface temperature $(T)$ field using pre-computed correlation factors $\left(F_{T}\right)$ derived from a 24-year (1988-2011) free-running Pac10 experiment (Exp.Pac10) without data assimilation (Oey et al. 2013). The free-running experiment was forced by the cross-calibrated multi-platform (CCMP; Atlas et al. 2009) from July 1987 to December 2009 and $0.5^{\circ} \times 0.5^{\circ} \mathrm{GFS}$ from January 2010 to December 2011 . The calculation was then repeated to yield a total of 48 years. The long-term integration ensures that a statistical equilibrium eddy field has been reached. The last 21-year (1991-2011) results are then used to compute the correlation factors which are then linearly interpolated onto the western North Pacific model grid. The analysis of potential temperature is computed as $T^{a}=T+F_{T}$ $\langle\eta\rangle$, where $\langle\bullet>$ denotes time averaging. The scheme therefore weighs more on using altimetry data in regions where the correlations between $\mathrm{T}$ and $\eta$ are high, but $T^{a} \approx T$ where the correlation is low. The details can be found in Yin and Oey (2007) and Oey et al. (2013). This experiment using the OI data assimilation scheme is ongoing from January 2012 through present; for comparison with LETKF, the results from January 1 to April 3, 2012 are used in this study (named Exp.OI). 


\section{LETKF}

An identical experiment as Exp.OI is conducted but with LETKF implemented into ATOP and assimilating the same SSHA data from AVISO (named Exp.LETKF). LETKF, first proposed by Ott et al. (2004) and modified by Hunt et al. (2007), solves the ensemble Kalman filter equations in local patches in a parallel computational setup. It uses the Gaussian approximation and employs an ensemble model to estimate the time evolution of the mean and background error covariance. The ensemble mean represents the maximum likelihood estimate of the analysis state.

Following Hunt et al. (2007), we start from an ensemble $\left\{x_{n-1}^{a\{i\}}: i=1,2, \ldots k\right\}$ of $m$-dimensional model state vectors at time $t_{n-1}$. According to the nonlinear model (mpiPOM in this study), each ensemble member produces a background ensemble $\left.x_{n}^{b\{i\}}: i=1,2, \ldots k\right\}$ at time $t_{n}$. The ensemble mean of the analysis is as follows:

$\bar{x}^{a}=\bar{x}^{b}+X^{b} \bar{w}^{a}$

where $\bar{x}=k^{-1} \sum x^{(i)}, X^{b}=x^{b(i)}-\bar{x}^{b}$, and $\bar{w}^{a}$ is calculated from the differénce between the observation at time $t_{n}$ and the ensemble forecasts multiplying the Kalman gain. The Kalman gain is obtained from the background error covariance, the observation error covariance, and an ensemble of background observation vectors using observation operator $H . \bar{x}^{a}$ represents the maximum likelihood estimate of the analysis state. Each ensemble member is updated using the following relation:

$x^{a(i)}=\bar{x}^{b} X b w^{a(i)}$

where $w^{a(i)}$ is the local weight vector, $w^{a(i)}=\bar{w}^{a}+W^{a(i)}$, and the matrix $W^{a}$ is computed from the symmetric square root of analysis error covariance. Spatial localization is implemented explicitly, considering only the observations from a region surrounding the model grids (Hunt et al. 2007). For a given grid point, a background ensemble of model state vectors $x^{b(i)}$ and local background observation ensemble $y^{b(i)}$ are selected and computed. The local weight vectors $w^{a(i)}$ are then calculated from $y^{b(i)}$ for a given local scale. A Gaussian-type weighting function $W$ (dist) of the observation localization is used for observational error covariance localization. $W($ dist $)=$ $\exp \left(-\operatorname{dist}^{2} / 2 \sigma^{2}\right)$, where dist and $\sigma$ denote distance from the center of the analysis grid and localization scale. We multiply the inverse of the weighting function to the observational error covariance. We define the horizontal localization scale as dist $_{\text {zero }}=2 \sigma_{\text {obs }} \sqrt{10 / 3}$, and vertical scale as dist $_{\text {zerov }}=2 \sigma_{\text {obsv }} \sqrt{10 / 3}$ (Miyazawa et al. 2012; Xu et al. $2013 \mathrm{a}, \mathrm{b}) . \sigma_{\mathrm{obs}}$ is represented by a number of grids, and $\sigma_{\mathrm{obsv}}$ is in meters. When the horizontal/vertical distance to the analysis grid point is larger than dist zero $/$ dist $_{\text {zerov }}$, zero covariance results. Thus, according to Eq. (2), the analysis ensemble $x^{a(i)}$ for the analysis grid is obtained using the background model states at the grid. The localization scales are 7 grids in the horizontal and $2,000 \mathrm{~m}$ in the vertical (Table 1). The horizontal scale corresponds approximately to the first-mode baroclinic Rossby radius (Oey et al. 2013) that determines the scales of the baroclinically unstable modes in the SCS. These choices of the LETKF parameters are based on our experience gained in modeling and data assimilations of eddies and strong western boundary currents in the Gulf of Mexico (Xu et al. $2013 \mathrm{a}, \mathrm{b}$ and references cited therein), a subtropical semi-enclosed sea which has many similar dynamical characteristics as those in the South China Sea. The vertical scale also approximates the scales of these unstable modes in deep waters (away from the shelves) of primary interest here (Chang and Oey 2013). As explained by Hunt et al. (2007), the flow may become locally unstable driven by regional dynamics, which can be better represented by a finitemember ensemble. Also, localization helps suppress spurious correlations (which result due to the limited sample size of the ensemble) between distant locations in the background error covariance matrix. Observation errors of the data increase with distance. As in Xu et al. (2013a, b; see also Miyazawa et al. 2012), we apply a factor

$\exp \left\{0.5\left[\left(\frac{\text { dist }_{\text {dist }}}{\text { dibs }^{2}}\right)^{2}+\left(\frac{\text { distv }_{\text {dist }}}{\text { dobs }}\right)^{2}\right]\right\}$,

where dist (distv) is the horizontal (vertical) distance of observation data to the target grid.

In practice, the ensemble Kalman filter equations may decouple from the "true" system. Model error is one reason, but even for a perfect model, the filter tends to underestimate the uncertainty in its state estimates, leading to overconfidence in the background estimates. In other words, the dynamics of the data assimilation ignores the observations when the discrepancy is too large. An ad hoc procedure to counter this tendency is to inflate either the background covariance or the analysis covariance during each assimilation cycle. In the study, a constant factor larger than 1 multiplies $W^{a}$ during each cycle. This method is called "multiplicative inflation." It reduces the influence of past observation on current analysis.

LETKF data assimilation is initialized on January 1, 2012, with 32 ensemble members. The initial members are randomly sampled from the outputs of the ongoing OI assimilative analyses, described previously, but excluding the dataassimilative analysis period from January 1 to April 3, 2012. The time interval for LETKF is 2 days. In the algorithm, the random samples are used to initialize LETKF iteration, and with injection of observations, the system becomes insensitive to the initial samples. The parameters (Table 1) are selected based on extensive sensitivity tests following the 
Table 1 LETKF parameters

\begin{tabular}{ll} 
Horizontal localization scale $\left(\sigma_{\mathrm{obs}} ;\right.$ number of grids $)$ & $7\left(0.7^{\circ}\right)$ \\
\hline Vertical localization scale $\left(\sigma_{\mathrm{obs}}\right)$ & $2,000 \mathrm{~m}$ \\
Covariance inflation & $21 \%$ \\
Observation error of SSHA & $0.1 \mathrm{~m}$ \\
Time interval of LETKF & 2 days \\
Ensemble members & 32 \\
\hline
\end{tabular}

methodologies which are described in details in $\mathrm{Xu}$ et al. (2013a). Our goal is not to repeat reporting these sensitivity tests; rather, as stated in Section 1, we will (i) demonstrate the first successful implementation of LETKF in SCS, (ii) show the robust three-layer circulation structures which were previously inferred based on sparse observations, and (iii) provide dynamical interpretations of the circulation structures.

\section{Comparing Exp.OI, Exp.LETKF, and observations}

Our goal here is to validate the model in three different ways. In Section 4.1, LETKF is compared with OI by assessing their results against AVISO A. In Section 4.2, we compare LETKF and $\mathrm{OI}$ analyses against temperature and salinity data from Argo floats. In Section 4.3, we describe the modeled Luzon Strait transports and compare them against transports estimated from observations and other model outputs.

\subsection{Comparisons against AVISO satellite observations}

The AVISO-gridded SSHA data is added to the mean sea surface height (SSH) from Rio et al. (2011), which is then used to compare against modeled SSH from Exp.OI and Exp.LETKF. While the comparison is not an independent check of the methods because AVISO is used in the assimilation, past experiences (Oey et al. 2005; Lin et al. 2007; Yin and Oey 2007; Oey et al. 2013; Xu et al. 2013a, b) have shown that the comparisons are useful as well as necessary. Moreover, data assimilation is not meant to merely duplicate observations. Rather, the assimilation scheme produces an analysis that takes into considerations of the model dynamics as well as model and observational errors, and the different estimates of the error covariances in LETKF and OI schemes can lead to different accuracies in the results. Figure 2 shows the evolution of SSH and surface currents from Exp.LETKF every 15 days from January 2,
Fig. 2 Daily-averaged SSH (colors in $\mathrm{m}$ ) and surface currents (squiggly black lines with scale shown) are shown every 15 days for the Exp.LETKF. Blue vectors are wind stresses with scale shown. Gray contour indicates the $200-\mathrm{m}$ isobaths. The magenta line indicates the $\mathrm{SSH}=0$ from AVISO gridded data
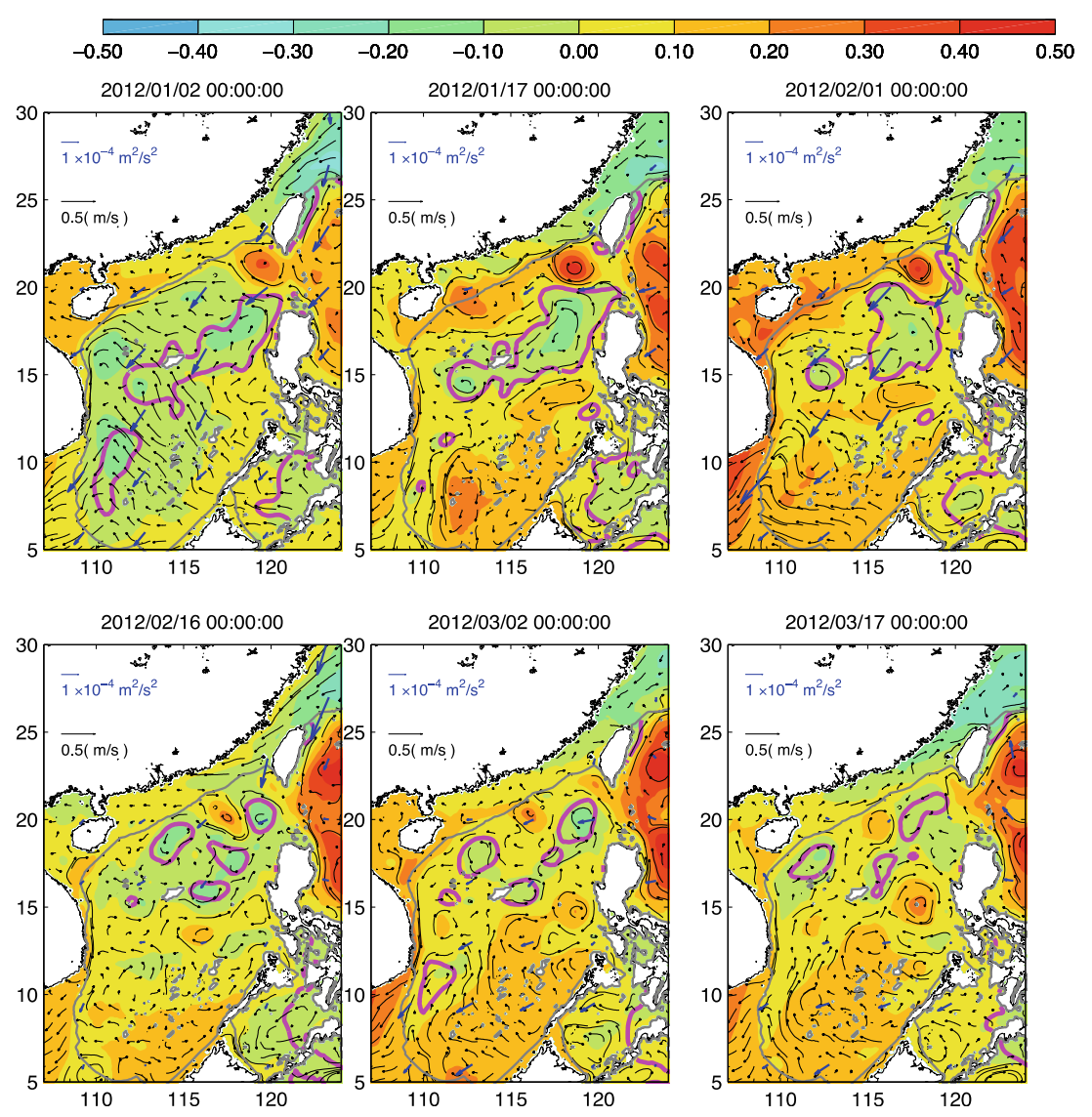
2012. The zero-contour (magenta) line from AVISO SSH separates regions of higher and lower SSH; its position is simulated well by the model. The Kuroshio intrudes into SCS and later a pair of warm and cold eddies were shed from the Kuroshio loop current; the eddies are simulated well by the model (see also Fig. 4 below), and they also compare well with the observational analyses of Zhang et al. (2013; see their Fig. 2).

To quantitatively evaluate and compare the model skills of Exp.OI and Exp.LETKF, time series of the spatial correlation coefficient and root mean square (RMS) errors between both models and AVISO SSHA are calculated and compared for the open-ocean region of the modeled western North Pacific in water deeper than $500 \mathrm{~m}$ (Fig. 3). Daily averaged output from Exp.OI and the ensemble mean of Exp.LETKF outputs are used to compute the correlations and RMS errors every 2 days (=LETKF assimilation interval). A 20-day adjustment period from the initial non-assimilated fields at January 1 , 2012 is omitted, and the comparison is done from January 20 to April 3. The Exp.OI correlation is about 0.60 on January 20; it increases to 0.69 on February 12 and oscillates thereafter around 0.66 until the end of the simulation (Fig. 3a). The corresponding mean correlation for the entire period is 0.65 . The Exp.LETKF correlation is higher, about 0.78 on January 20 and it increases to 0.83 on February 6. Thereafter, the correlation oscillates but is consistently above the Exp.OI. The overall mean correlation is 0.77 , which is $18 \%$ larger than that of Exp.OI. In Fig. 3b, the mean RMS error for Exp.OI is 0.204 while that for Exp.LETKF is 0.112 - a $50 \%$ reduction.

An example of Exp.LETKF SSH on January 29, 2012 is compared against AVISO SSH in Fig. 4. Surface currents from Exp.LETKF and geostrophic currents estimated from AVISO SSH are also compared. In SCS, both AVISO and model show a warm eddy west of Luzon Strait, as well as low sea level and cyclonic circulation south of the eddy. In the Kuroshio and region to the east, model and observed SSH also agree well. To further evaluate the effectiveness of Exp.LETKF, we compare Exp.LETKF and Exp.OI by plotting maps of their spatial correlations with AVISO SSH (Fig. 5). In the open oceans of the western North Pacific and in the northern half of the SCS, Exp.LETKF shows higher correlations ( 0.8) than Exp.OI $(0.4 \sim 0.6)$. We also compare the corresponding RMS errors; plots are not shown as the errors are in most deep regions $(H>$ $500 \mathrm{~m}$ ) less than 0.1 which is approximately twice the standard error of altimetry measurements (Rio et al. 2011; c.f. Fig. 3b). Over the continental shelf regions, Exp.LETKF also has higher correlations and lower RMS errors than Exp.OI. However, the AVISO SSH data has larger uncertainty near the
Fig. 3 Comparison between AVISO-gridded SSHA data and the SSHA from the two dataassimilative experiments (OI (dash) and LETKF (solid)). Top: spatial correlation coefficient between the model and AVISO SSHAs over water region deeper than $500 \mathrm{~m}$ in the western North Pacific, from January 20 to April 3, 2012. Bottom: the corresponding RMS error for the same region
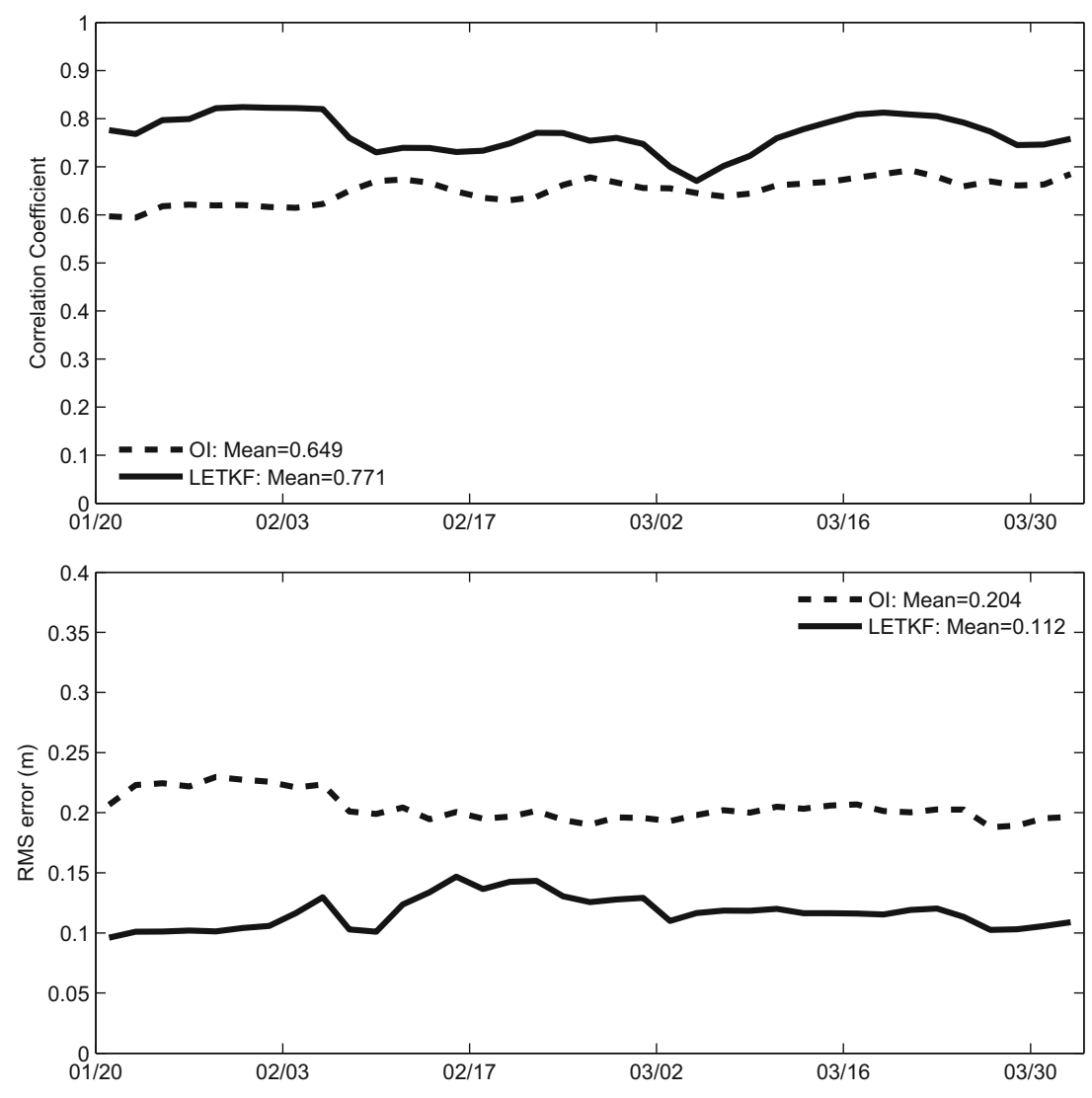
Fig. 4 Comparison of Exp.LETKF SSH and surface $(u, v)($ left $)$ against AVISO SSH and geostrophic velocity (right) on January 29, 2012. Blue vectors are wind stresses with scale shown. White contour indicates the 200-m isobath. The magenta line indicates the $\mathrm{SSH}=0$ from AVISO data

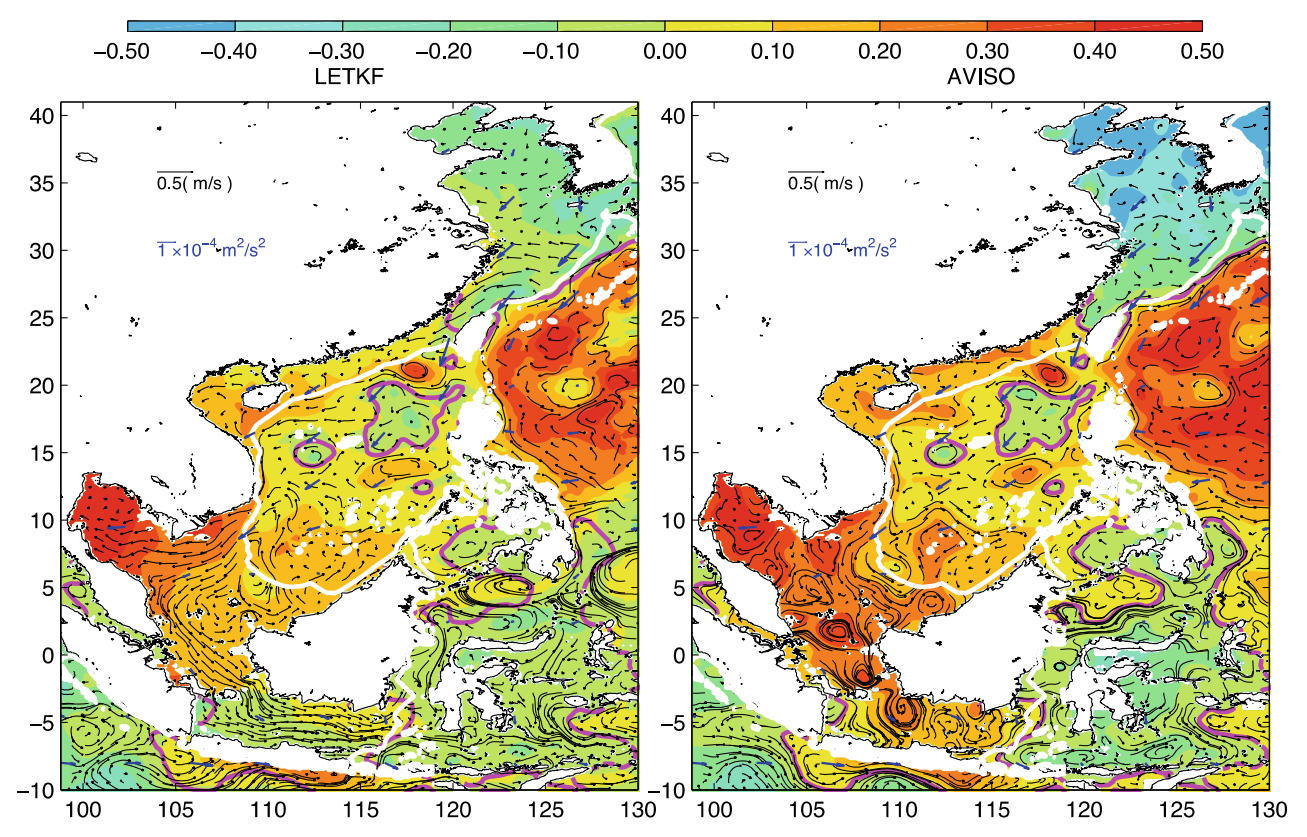

coasts. Future work should evaluate the models near the coasts using in situ observations.

The reduction of analysis errors of LETKF compared with those of OI is consistent with our previous experiences using these two methods in western boundary regions with strong mesoscale features ( $\mathrm{Xu}$ et al. 2013a); as detailed in that paper, LETKF benefits from its use of the time-evolving error covariance (see their Fig. 3 and discussions).

\subsection{Comparisons against Argo float data}

We assess model skills using independent temperature $(T)$ and salinity $(S)$ data obtained from the Argo dataset. The Argo data were collected and made freely available by the Coriolis project and programs that contribute to it (http://www.coriolis. eu.org). Seven Argo floats during the assimilation period are available for comparison (see locations in Fig. 1). Examples of vertical profiles of $T$ and $S$ from two Argo floats (one in northern SCS and one east of Taiwan) and Exp.LETKF are shown in Fig. 6. In general, the models $T$ and $S$ agree well with Argo in layers deeper than $\sim 400 \mathrm{~m}$. Near the surface, the model overestimates temperature at both locations, and there is a mismatch between model surface salinity and Argo. The discrepancy is largest for the first location which is over the shelfbreak where data assimilation has been deliberately turned off (c.f. Oey et al. 2014). Another reason may be due
Fig. 5 Correlations with AVISO SSHA of OI-simulated SSHA (left) and of LETKF-simulated SSHA (right) on January 29, 2012. Regions with correlations greater than 0.6 and 0.8 are light and dark shaded, respectively
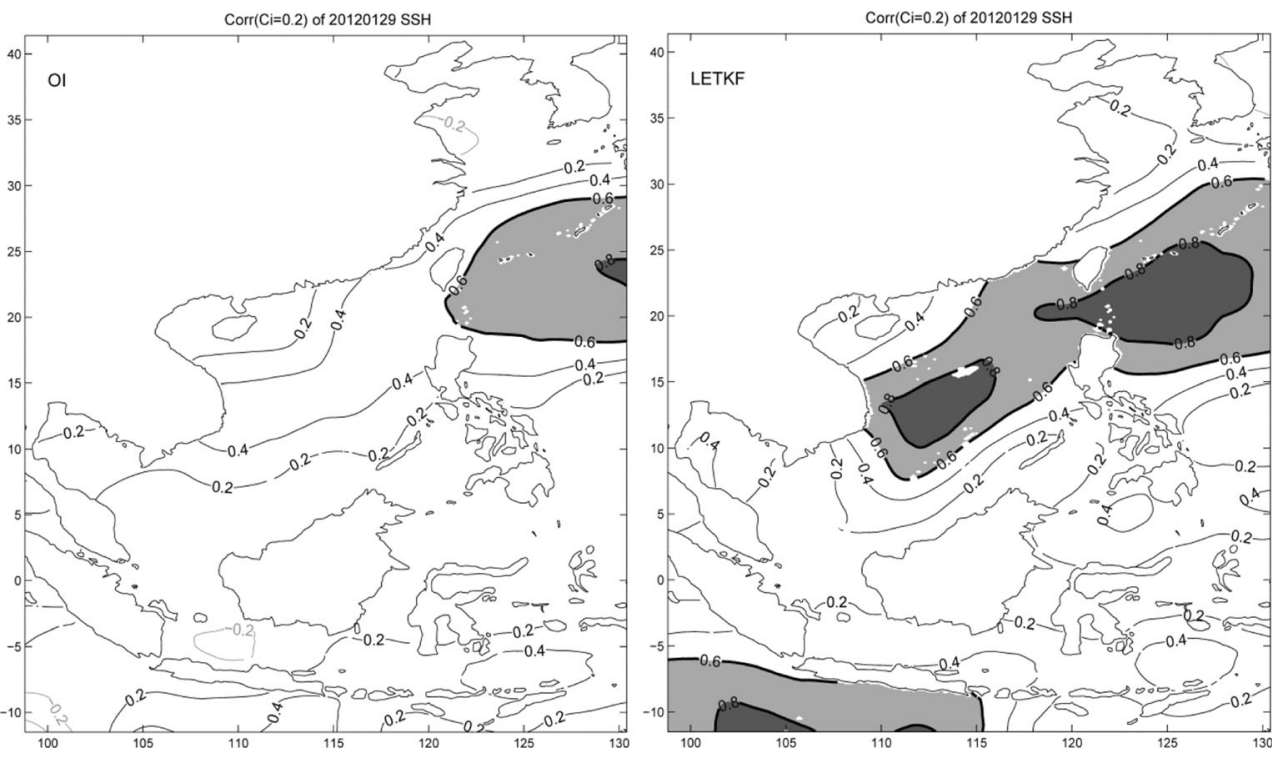
Fig. 6 Vertical profiles of Argo (solid line) temperature ( $T$, left) and salinity $(S, r i g h t)$ and $T$ and $\mathrm{S}$ from LETKF (asterisks) at $\left(118^{\circ}\right.$ E, $20.8^{\circ} \mathrm{N}$; top $)$ and $\left(125^{\circ} \mathrm{E}\right.$, $23.5^{\circ} \mathrm{N}$; bottom). The skills, RMS errors, and biases of LETKF compared with Argo data are listed in Table 2
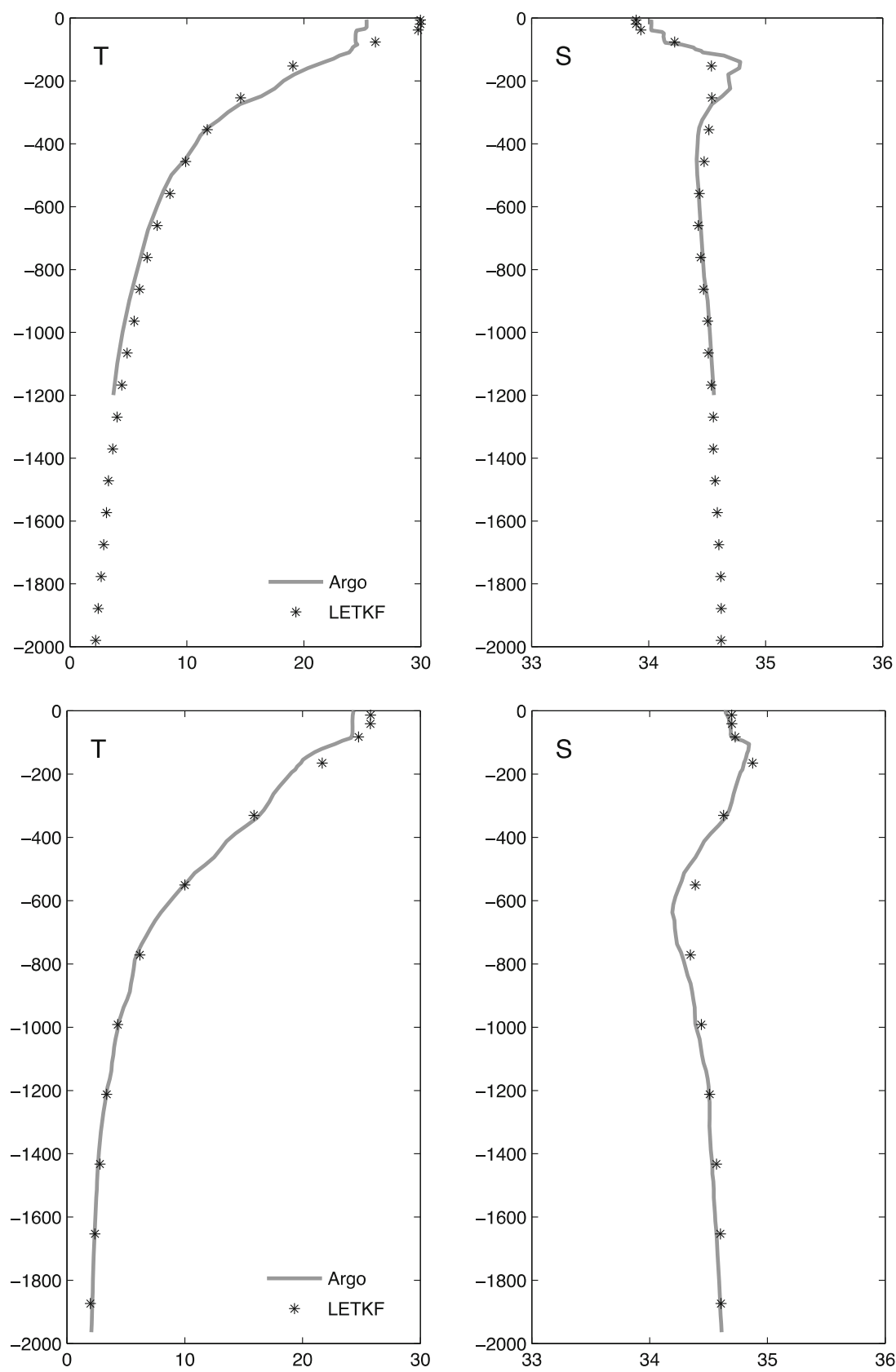

to the use of relaxation of the model SST and salinity towards monthly climatology, while Argo data is a snapshot. On the other hand, the subsurface salinity maximum at $\left(118^{\circ} \mathrm{E}, 20.8^{\circ} \mathrm{N}\right)$ and a depth of about $200 \mathrm{~m}$ is simulated by Exp.LETKF, although the value is weaker than observed. The subsurface salinity maximum indicates the existence of North Pacific tropical water $(\mathrm{Qu}$ 2000), and its presence at the Argo location in SCS indicates that the model simulates water mass intrusion from the open Pacific Ocean. The salinity minimum is also simulated, although it is also less distinct than is shown by the Argo data.
Given time series from model $m_{i}$ and observation $o_{i}$, we define (Willmott 1981):

Skill $=1-<\left(m_{i}-O_{i}\right)^{2}>/<\left(\left|m_{i}-<m>\right|+\left|o_{i}-<o>\right|\right)^{2}>$

where $<>$ denotes the mean and || denotes the absolute value. The Skills are computed separately for $T$ and $S$. The value $=1$ means a perfect agreement, while 0 means a complete mismatch. RMS error is defined as $<\left(m_{i}-o_{i}\right)^{2}>^{1 / 2}$, and bias is | $<\left(m_{i}-o_{i}\right)>\mid$. The averaged skills, RMS errors, and biases for 
the seven Argo floats data for Exp.LETKF and Exp.OI are listed in Table 2. Model skills for $T$ and $S$ are high $(\geq 0.86)$. The Exp. OI achieves better skill in $S$ than Exp. LETKF. However, the RMS errors and biases for $T$ are larger for Exp. OI than Exp.LETKF.

\subsection{Transports through the Luzon Strait and other sections and comparison with literature}

Figure 7 shows the mean zonal velocity in the Luzon Strait for both Exp.OI and Exp.LETKF (see Fig. 1 for transect location). The maximum water depth reaches $\sim 3,400 \mathrm{~m}$ along this transect. For both experiments, in the upper layer (shallower than $\sim 500 \mathrm{~m}$ ), the flow is eastward (outflow from SCS) immediately south of Taiwan and is generally westward (inflow into SCS) in the middle and southern portions of the strait. Thus, the Kuroshio loops into the SCS in the southern portion of the Luzon Strait, and (most of it) exits through the northern portion. The Exp.LETKF shows a weak outflow immediately north of Luzon and a more uniform inflow (than Exp.OI) in the middle portion of the strait. In the vertical, both experiments show a three-layer structure of the zonal velocity across most of the strait. There is inflow into the SCS near the surface, outflow in the middle, and inflow near the bottom. The three-layer structure has previously been inferred based on observations and water mass analyses (Chen and Huang 1996; Qu 2000; Qu et al. 2006b, Tian et al. 2006, Yang et al. 2010). Tian et al. (2006) estimated the LST in October 2005 from 65 full-depth current profiles at 15 stations and showed that the LST was $-9.0 \mathrm{~Sv}\left(1 \mathrm{~Sv}=10^{6} \mathrm{~m}^{3} \mathrm{~s}^{-1}\right)$ in the upper layer $(z>-500 \mathrm{~m}), 5.0 \mathrm{~Sv}$ in the middle layer $(-1,500 \sim-500 \mathrm{~m})$, and $-2.0 \mathrm{~Sv}$ in the lower layer $(z<-1,500 \mathrm{~m})$. Their observed values are shown as entry \#1 in Table 3 which also shows observed estimates from other researchers (entries \#2-7).

In the upper layer, all of the observed transport estimates, except for Yang et al. (2010), are westward into the SCS and range from $-0.8 \mathrm{~Sv}$ (Yuan et al. 2008b) to as much as $-10.3 \mathrm{~Sv}$ (Liao et al. 2008). The durations of observations were from a few days to 1 month in different seasons; the shortness of the observation periods may explain the large variability of the transport estimates. For example, Yang et al. (2010) attributed the large outflow transport $(+5 \mathrm{~Sv})$ in the upper layer to the

Table 2 Averaged model skill, root mean squared (RMS) errors, and bias, evaluated from Argo temperature $(T)$ and salinity $(S)$ data

\begin{tabular}{|c|c|c|c|c|c|c|}
\hline & \multicolumn{2}{|c|}{ Skill } & \multicolumn{2}{|c|}{ RMS errors } & \multicolumn{2}{|l|}{ Bias } \\
\hline & $T$ & $S$ & $T\left({ }^{\circ} \mathrm{C}\right)$ & $S$ (PSU) & $T\left({ }^{\circ} \mathrm{C}\right)$ & $S$ (PSU) \\
\hline Exp.LETKF & 0.98 & 0.86 & 1.74 & 0.13 & 0.94 & 0.04 \\
\hline Exp.OI & 0.92 & 0.90 & 1.82 & 0.12 & 0.99 & 0.07 \\
\hline
\end{tabular}

$T$ temperature, $S$ salinity, $P S U$ practical salinity units presence of an anticyclonic eddy east of the Luzon Strait during their observation. In the middle layer, all observed estimates show outflow transports $\approx 0.22 \sim 5 \mathrm{~Sv}$ from SCS into the North Pacific Ocean. In the lower layer, westward inflows ranging from -0.1 to $-2 \mathrm{~Sv}$ prevail. Wyrtki (1961; see also $\mathrm{Qu}$ et al. 2006b) suggested that the near-bottom inflow of Pacific water may be driven by the baroclinic pressure gradient induced by density difference between the open Pacific and SCS waters.

In order to compare with the observed estimates, we use the same depth ranges as used by Tian et al. (2006), 0-500, 5001,500 , and $1,500 \mathrm{~m}$-bottom, to calculate the corresponding three-layer transports for Exp.OI and Exp.LETKF and obtain -3.7 and $-5.5 \mathrm{~Sv}$ in the upper layer, 5.6 and $4.8 \mathrm{~Sv}$ in the middle, and -1.5 and $-1.7 \mathrm{~Sv}$ for the lower layer (Table 3, entries 8 and 9). These model transports are within the range of the observed estimates. Most importantly, the models show a robust three-layer transport structure, which is particularly distinct in the case of Exp.LETKF (Table 3, entry \#9). The modeled deep inflows occur inside deep troughs in the strait where the current speeds are strong $0.3 \sim 0.4 \mathrm{~m} \mathrm{~s}^{-1}$ (Fig. 7) suggesting a topographically controlled deep flow (Whitehead et al. 1974; Qu et al. 2006b).

For Exp.LETKF, the 3-month mean total LST for Exp.LETKF is $-2.4 \mathrm{~Sv}$, westward, into the SCS (Fig. 8). However, the total transport for Exp.OI is nearly zero (Table 3). Estimates of LST from other observations and models are also westward in winter. For example, the mean LST in winter was $-2.75 \mathrm{~Sv}$ (Wyrtki 1961), -5.3 Sv (Qu 2000), and $-4.8 \mathrm{~Sv}$ (Yaremchuk and Qu 2004). Estimates based on models show that the mean LST in winter ranges from between -3.1 (Rong et al. 2007) and $-12.2 \mathrm{~Sv}$ (Song 2006). The large range for model estimates probably reflects differences in topography representation, grid resolution, and numerical models.

Comparisons of the Kuroshio transports east of Luzon and southeast of Taiwan (see Fig. 1 for transect locations) against other published modeled and observed transports are also conducted. For Exp.LETKF, the upper 500-m transport averaged over the simulation period is $22.6 \mathrm{~Sv}$ east of Luzon at $18^{\circ}$ $\mathrm{N}$ and $20.3 \mathrm{~Sv}$ southeast of Taiwan. Estimates of the transport are $15 \sim 35 \mathrm{~Sv}$ east of Luzon at $18^{\circ} \mathrm{N}$ by Sheu et al. (2010) and approximately 21 22 Sv northeast of Taiwan by Johns et al. (2001). The present modeled transports generally agree with these estimates. Note that the transport difference between the southern and northern transects of the Kuroshio (north minus south) is $-1.3 \mathrm{~Sv}$, which is smaller in magnitude than the transport into the SCS of $-5.5 \mathrm{~Sv}$. It indicates that there is a large amount of water $(\sim-4.2 \mathrm{~Sv})$ coming from the open Pacific Ocean. This result is consistent with the idea in the literature that there is intrusion of Pacific waters into the SCS. The intrusion could be induced by the large-scale meridional gradient of the wind stress curl and pressure gradient setup in 
Fig. 7 Zonal velocity $\left(\mathrm{cm} \mathrm{s}^{-1}\right)$ in the Luzon Strait (at $121.6^{\circ} \mathrm{E}$; see Fig. 1 for transect location) averaged from January 20 April 2003 for Exp.OI (upper) and Exp.LETKF (middle) and for unassimilated run Exp.Pac10 averaged from 1991 to 2008 (bottom). Negative values are shaded and indicate flow into SCS from the North Pacific Ocean
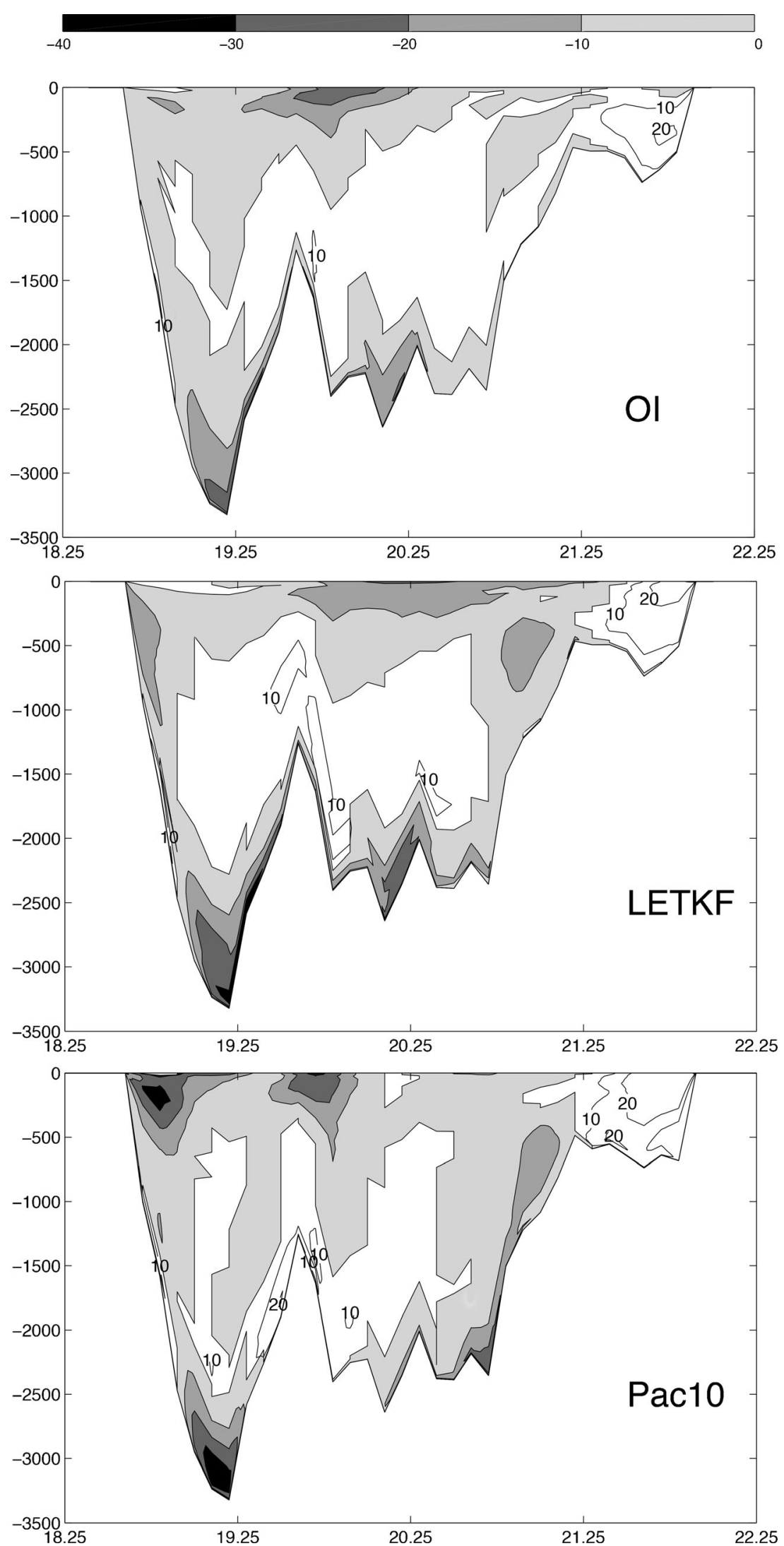
Table 3 Luzon Strait transports (Sv) from observations and models

\begin{tabular}{|c|c|c|c|c|c|}
\hline \multirow[t]{2}{*}{ Authors } & \multicolumn{5}{|c|}{ Transport (Sv) } \\
\hline & $\begin{array}{l}\text { Total (BI) } \\
0 \text {-bottom }\end{array}$ & $\begin{array}{l}\text { Upper } \\
0-500 \mathrm{~m}\end{array}$ & $\begin{array}{l}\text { Middle } \\
500-1,500 \mathrm{~m}\end{array}$ & $\begin{array}{l}\text { Lower } \\
1,500 \text {-bottom }\end{array}$ & Time \\
\hline 1. Tian et al. (2006) & $-6(10.5)$ & -9 & 5 & -2 & October 4 to 6,2005 \\
\hline 2. Liao et al. (2008) & $\begin{array}{l}-7.2 \\
0-2,000 \mathrm{~m}\end{array}$ & $\begin{array}{l}-10.3 \\
0-400 \mathrm{~m}\end{array}$ & $\begin{array}{l}3.1 \\
400-2,000 \mathrm{~m}\end{array}$ & & November 28 to December 27, 1998 \\
\hline 3. Yuan et al. (2008a) & $-3.5(2.1)$ & $\begin{array}{l}-3.5 \\
0-400 \mathrm{~m}\end{array}$ & $\begin{array}{l}0.22 \\
400-1,200 \mathrm{~m}\end{array}$ & $\begin{array}{l}-0.22 \\
1,200 \text {-bottom }\end{array}$ & August 28 to September 10, 1994 \\
\hline 4. Yuan et al. (2008b) & & $\begin{array}{l}-0.8 \\
0-400 \mathrm{~m}\end{array}$ & $\begin{array}{l}2.4 \\
500-1,200 \mathrm{~m}\end{array}$ & & March 17 to April 15, 2002 \\
\hline 5. Yuan et al. (2009) & $-3(7.1)$ & $\begin{array}{l}-6.6 \\
0-400 \mathrm{~m}\end{array}$ & $\begin{array}{l}3.7 \\
400-2,000 \mathrm{~m}\end{array}$ & $\begin{array}{l}-0.1 \\
1,200 \text {-bottom }\end{array}$ & March 8 to 27,1992 \\
\hline 6. Zhou et al. (2009) & $\begin{array}{l}-3.25 \\
0-1,500 \mathrm{~m}\end{array}$ & -4.37 & 1.12 & & September 18 to 202006 \\
\hline 7. Yang et al. (2010) & $5.5(1.0)$ & 5 & 2.5 & -2 & July 5 to 14,2007 \\
\hline 8. Exp.OI & $-0.4(8.2)$ & -3.7 & 5.6 & -1.5 & January 20 to April 3, 2012 \\
\hline 9. Exp.LETKF & $-2.4(8.4)$ & -5.5 & 4.8 & -1.7 & January 20 to April 3, 2012 \\
\hline \multicolumn{6}{|l|}{ 10. Pac10 } \\
\hline Mean & $-5.0(6.6)$ & -4.3 & 2.7 & -3.4 & 1991-2008 \\
\hline JFM & $-6.7(7.4)$ & -6.7 & 2.7 & -2.7 & Winter \\
\hline AMJ & $-4.0(5.9)$ & -3.5 & 2.6 & -3.1 & Spring \\
\hline JAS & $-3.1(5.5)$ & -1.8 & 2.6 & -3.9 & Summer \\
\hline OND & $-6.1(7.3)$ & -5.1 & 2.8 & -3.8 & Fall \\
\hline $\begin{array}{l}\text { 11. Zhang et al. (2010) } \\
\text { Global HYCOM }\end{array}$ & $-1.9(4.6)$ & $\begin{array}{l}-4.4 \\
0-300 \mathrm{~m}\end{array}$ & $\begin{array}{l}-2.2 \\
300-1,200 \mathrm{~m}\end{array}$ & $\begin{array}{l}4.7 \\
1,200 \text {-bottom }\end{array}$ & 2005-2006 \\
\hline $\begin{array}{l}\text { 12. Hsin et al. (2012) } \\
\text { Regional POM }\end{array}$ & -4.0 & $\mathrm{~N} / \mathrm{A}^{\mathrm{a}}$ & $\mathrm{N} / \mathrm{A}^{\mathrm{a}}$ & $\mathrm{N} / \mathrm{A}^{\mathrm{a}}$ & 2002-2008 \\
\hline
\end{tabular}

The free-running Pac10 results are also shown over four seasons: January, February, and March; April, May, and June; July, August, and September); and October, November, and December. Headings show depth ranges of the upper, middle, and lower layers, but different specific ranges used in some of the estimates in the literature are presented. BI is defined in equation (4). In the transport entries, depth ranges different from the headings are indicated JFM January, February, March; AMJ April, May, June; JAS July, August, September; OND October, November, December

${ }^{a}$ Values not reported. Authors' Fig. 6 indicates a two-layer structure: inflow from 150-1,200 m and outflow below 1,200 m; the latter is similar to Zhang et al. (2010)

the Pacific (Chang and Oey 2012), the local wind stress curl over the Luzon Strait in winter (Metzger and Hurlburt 1996), and westward propagating subtropical counter current eddies (Chang and Oey 2012).
Fig. 8 Total transport for the four straits that connect SCS to outside seas: Karimata Strait, Sibutu Passage, Taiwan Strait, and Luzon Strait, for Exp. LETKF. Signs of transports are negative westward or southward

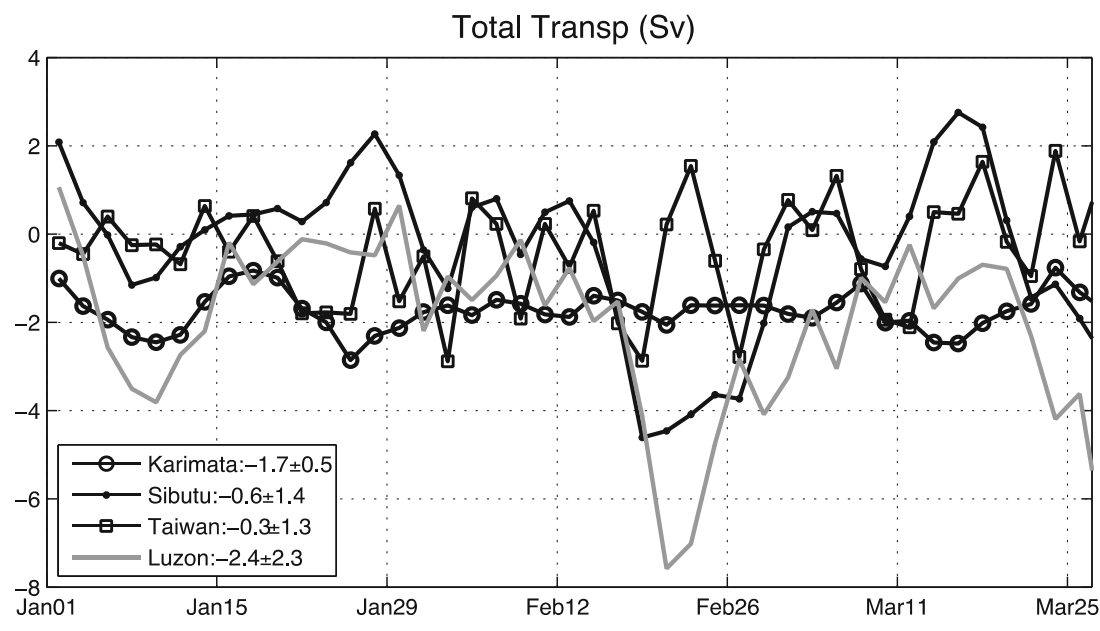


The Luzon Strait is the only deep channel that connects the SCS with the Pacific Ocean. In the model, the sill depth of the Luzon Strait is $2,000 \mathrm{~m}$, below which the SCS is therefore completely closed. The second and third deepest straits are Mindoro-Panay strait which is about $570 \mathrm{~m}$ and the Balabac Strait which is $\sim 130 \mathrm{~m}$ both connecting SCS to the Sulu Sea. South of the Sulu Sea, the Sibutu Passage sill is $\sim 235 \mathrm{~m}$, and southwest of SCS, the Karimata Strait is $\sim 50 \mathrm{~m}$. To the north, the Taiwan Strait is $\sim 70 \mathrm{~m}$. We compute LETKF transport time series through Taiwan, Luzon, Sibutu, and Karimata straits (Fig. 8; for locations, see Fig. 1) which together enclose SCS. The LST is highly variable; some of the strong inflow transport appear to be related to the strong winter monsoon wind, e.g., in middle to end of February of 2012 (Oey et al. 2014). The mean Karimata transport and transport through Sibutu passage are negative, i.e., outflow from SCS, although the Sibutu transport $(-0.6 \pm 1.4 \mathrm{~Sv})$ is not significantly different from zero. The mean Taiwan Strait transport is about -0.3 $\pm 1.3 \mathrm{~Sv}$, but it too does not differ significantly from zero, consistent with transport observations in the strait under strong northeasterly monsoon winds in winter (Lin et al. 2005).

\section{The three-layer circulation structure of the Luzon Strait and South China Sea}

The three-layer structure of the LST appears to be a robust observed feature which may be dynamically related to the circulation of the SCS. The model of Chao et al. (1996; see their Figs. 2, 3, and 4 and descriptions) appears to indicate inflow at $z=-150 \mathrm{~m}$, outflow at $z=-900 \mathrm{~m}$, and inflow at $z=$ $-2,000 \mathrm{~m}$ in the Luzon Strait, but no integrated transports were given. Xue et al. (2004) were interested more in horizontal rather than vertical structure of the LST; it is difficult to discern a three-layer vertical structure from their results (see their Fig. 10 and descriptions). In the near-global model (based on MOM) of Qu et al. (2006a), interleaving inflows and outflows exist below $400 \mathrm{~m}$, but the authors stated that the simulated LST did not show a three-layer structure in the vertical (see their p. 3648, Section 4a). Zhang et al. (2010) analyzed 2-year (2005-2006) mean LST using the outputs from a data-assimilated global model (based on the HYCOM) and compared them with the observations of Tian et al. (2006). Depth ranges $(0-300,300-1,200$, and 1,200 m-bottom) different from those used by Tian et al. (2006; see Table 3) were used to define the upper, middle, and lower layers. The results (Table 3 entry \#11) show westward inflows into SCS in the upper and middle layers and outflow into the North Pacific Ocean in the lower layer. Hsin et al. (2012) computed 7-year mean (2002-2008) LST from a regional model (based on POM) and concluded that there is "...outflow from 20 to $150 \mathrm{~m}$, inflow from 150 to $1,200 \mathrm{~m}$, outflow from 1,200 to 2,300 m, and little net transport below that" (see paragraph 16 of their paper). Except for the outflow in the near-surface layer, their Fig. 6 basically indicates a two-layer structure: inflow from 150 to $1,200 \mathrm{~m}$ and outflow below $1,200 \mathrm{~m}$; the latter is similar to the result of Zhang et al. (2010).

For both Exp.OI and Exp.LETKF, we have shown above that a three-layer structure of the LST exists, but since these model analyses are only for 3 months, it is necessary to confirm that the three-layer structure seen in them is a robust dynamical feature and not merely a product of data assimilation. We therefore compute the three-layer transports using the second repeat of the 48-year long-term ATOP simulation without data assimilation (Exp.Pac10), as described previously in Section 2. The first 3.5 years of that simulation is omitted to ensure that the model has sufficient time to adjust to the (repeated) CCMP wind which starts in July of 1987; for SCS, the adjustment time is 2 3 years (Chang and Oey 2012). Eighteen-year averaged transports, from 1991 to 2008, and the corresponding seasonal values for winter (JFM), spring (AMJ), summer (JAS), and fall (OND), in the upper, middle, and lower layers are then computed (Table 3 entry \#10; Fig. 7 bottom panel). These show a three-layer structure that is consistent with Exp.LETKF and Exp.OI (Fig. 7). The structure persists irrespective of the seasons. The strength is measured by BI, which is the average of the differences between the middle- and upper-layer transports and the middle- and lower-layer transports:

$\mathrm{BI}=\{($ Middle-Upper $)+($ Middle - Lower $)\} / 2$

The BI is strong during fall and winter (7.3 7.9), and weak in summer and spring (5.5 5.9), which are consistent with the available observed variation in Table 3: entries 1 and 5 (average $\approx 8.8$ ) for fall-winter and entries 3 and 7 for summer (average $\approx 1.6$ ). In particular, in the upper layer, the strongest inflow occurs during fall $\sim$ winter and weakest in summer (JAS), while in spring (AMJ), the value is intermediate. The variation is consistent with those published in the literature (e.g., see Sheu et al. 2010 and references quoted therein). The time series of the total and upper-layer transports, from 1991 to 2008, are shown in Fig. 9, and they are compared with observations, showing reasonable agreements. Discrepancies are in part due to incomplete model physics and numerical truncation errors, but they are probably also caused by shortterm durations of the observations. Figure 9 (bottom panel) shows the long-term (1991-2008) mean zonal velocity profile in the Luzon Strait, showing the distinct three-layer structure: inflow from the surface to $z \approx-570 \mathrm{~m}$, outflow below $z \approx$ $-570 \mathrm{~m}$ through $z \approx-1,600 \mathrm{~m}$ to $-1,800 \mathrm{~m}$, and inflow below that in the lower layer. To the best of our knowledge, this is the first time that such a structure has been clearly revealed. 
Fig. 9 Upper two panels: Time series of Luzon Strait transports from 1991 to 2008 for total and upper 500-m transports. Red asterisks show observed estimates (see Table 3). Bottom panel: Time (1991-2008) and width-averaged zonal current (solid) in the Luzon Strait showing the three-layer velocity structure and the corresponding standard deviation (dashed) both in centimeter per second
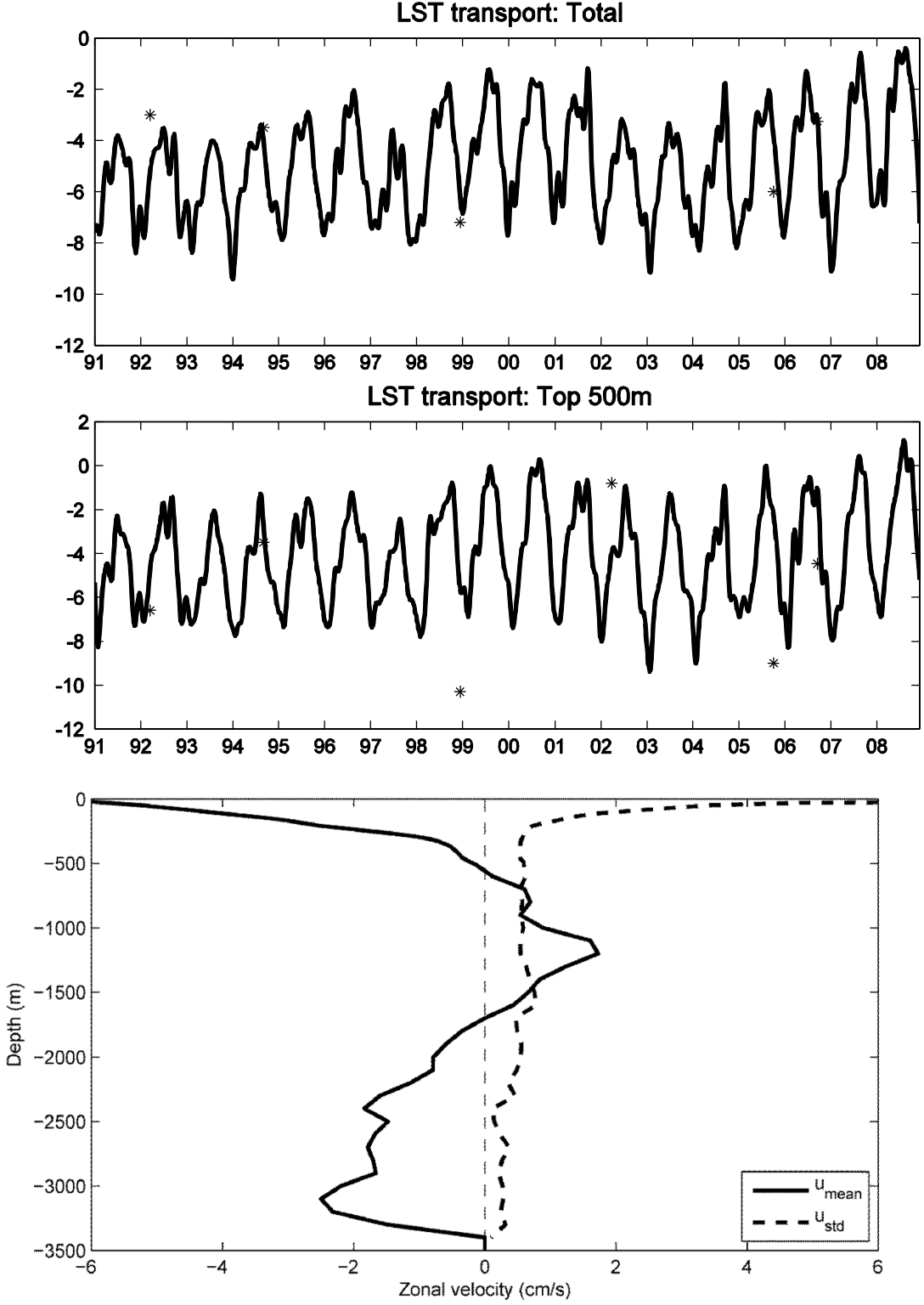

\subsection{Mean circulation in the South China Sea}

The three-layer structure in the Luzon Strait suggests different circulation patterns in the upper, middle, and lower layers of the SCS. This section seeks to explain these mean circulation patterns using the long-term (1991-2008) unassimilated simulation Exp.Pac10. To do that, we divide SCS into layers according to the sill depths of the straits that connect the SCS to the oceans outside. The Luzon Strait is deepest with a sill depth of 2,000 m below which the SCS is completely closed (Fig. 10, right). The second deepest strait is the Mindoro/Panay Strait $\left(121^{\circ} \mathrm{E}, 12^{\circ} \mathrm{N}\right)$ connecting the SCS to the Sulu Sea; it has a sill depth of $570 \mathrm{~m}$ below which the SCS therefore only has one opening at the Luzon Strait (Fig. 10, middle). The third deepest strait is the Balaca Strait $\left(117^{\circ} \mathrm{E}, 8^{\circ} \mathrm{N}\right)$ which also connects SCS to the Sulu Sea and which in the model has a sill depth of $120 \mathrm{~m}$ (the higherresolution ETOPO2 shows $132 \mathrm{~m}$ ). Below this depth, the SCS therefore has two openings: Luzon and Mindoro-Panay Straits (Fig. 10, left). Elsewhere in SCS, the water depth is shallower than $120 \mathrm{~m}$. We therefore divide SCS into four layers: (i) surface layer $0 \geq z>-120 \mathrm{~m}$; (ii) upper layer $-120 \mathrm{~m} \geq z>-570 \mathrm{~m}$; (iii) middle layer $-570 \mathrm{~m} \geq z>$ $-2,000 \mathrm{~m}$; and lower or abyssal layer $-2,000 \mathrm{~m} \geq z>-\mathrm{H}$ (bottom), where $\mathrm{H}=$ water depth.

The surface layer is considered to be driven by eddies and other fast and energetic processes. Below, we only implicitly consider this layer through the Ekman pumping that it imparts onto the layer immediately below-i.e., the upper layer. The goal is to explain the basin-scale, long-term mean circulations 
Fig. 10 Topography of SCS shaded for water depths shallower than (left) $120 \mathrm{~m}$ showing two openings (Luzon and MindoroPanay (near $12 \mathrm{~N}$ and $121 \mathrm{E}$ ) Straits), (middle) shallower than $570 \mathrm{~m}$ showing one opening (Luzon Strait), and (right) shallower than 2,000 $\mathrm{m}$ showing that SCS is completely closed below the sill depth of the Luzon Strait at 2,000 m

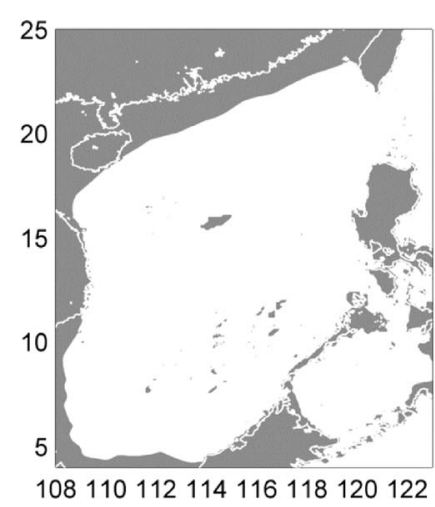

108110112114116118120122

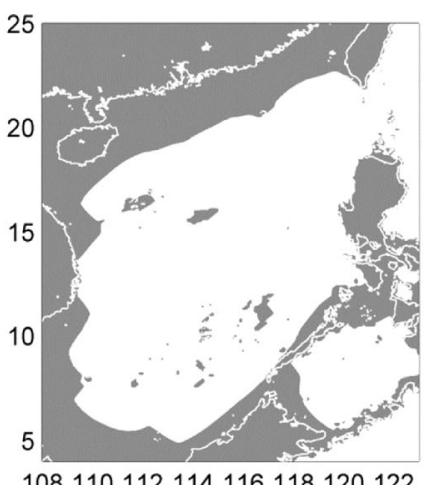

108110112114116118120122

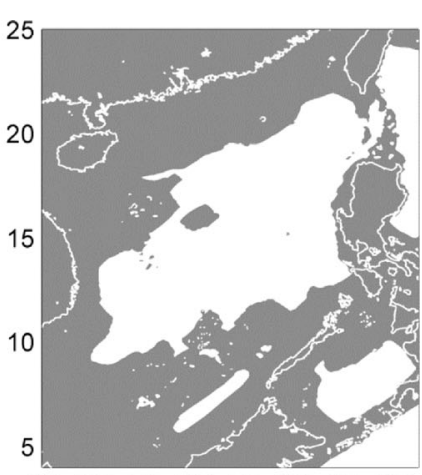

108110112114116118120122 in the three subsurface layers and how they may relate to the Luzon transports.

We examine the time-averaged SCS basin-scale circulation patterns depth-averaged for $-120 \geq z>-570 \mathrm{~m},-570 \mathrm{~m} \geq z>$ $-2,000 \mathrm{~m}$, and $2,000 \mathrm{~m} \geq z>-\mathrm{H}$. The $570 \mathrm{~m}$ is chosen to coincide with the sill depth of Mindoro Strait, the second deepest strait of the SCS. Figure 11 shows the circulation patterns. The circulation is cyclonic in the upper layer, anticyclonic in the middle layer, and generally cyclonic in the deep abyssal layer except near the southwest corner of the SCS where an anticyclonic eddy appears. A deep western boundary current appears in the northern basin due to the Luzon Strait overflow and the $\beta$ effect, which is consistent with Wang et al. (2011) and Lan et al. (2013).

In order to explain the above three-layer circulation patterns, a simplifying assumption is made that for long-term mean, large basin-scale (SCS) circulations, the three layers may be approximately treated independently but for mass fluxes across interfaces between the layers and from side boundaries. The validity of this assumption is checked a priori by comparing the prediction with the simulated results described above. The one-layer reduced gravity equations are as follows:

$D h / D \mathrm{t}+h \nabla \cdot \mathbf{u}=Q^{-} \kappa \eta$

$\partial \mathbf{u} / \partial \mathrm{t}+\mathbf{k}(\mathrm{f}+\zeta) \times \mathbf{u}=-\nabla\left(g^{\prime} h+|\mathbf{u}|^{2} / 2\right)+\tau / H-r \mathbf{u}$

where $h=H+\eta, H(x, y)=$ mean water depth, $\eta(x, y, t)=$ layer anomaly (i.e., deviation from $H), \nabla=(\partial / \partial x, \partial / \partial y), \mathbf{u}=(u, v)$ is the horizontal velocity, $g^{\prime}=g \Delta \rho / \rho_{\mathrm{o}}$ is the reduced gravity,
Fig. 11 Eighteen-year (19912008) mean currents from Exp.Pac10, depth-averaged in the upper (left column), middle (middle column), and bottom (right column) layers as indicated. Shaded region indicates topographic depths shallower than $2,000 \mathrm{~m}$
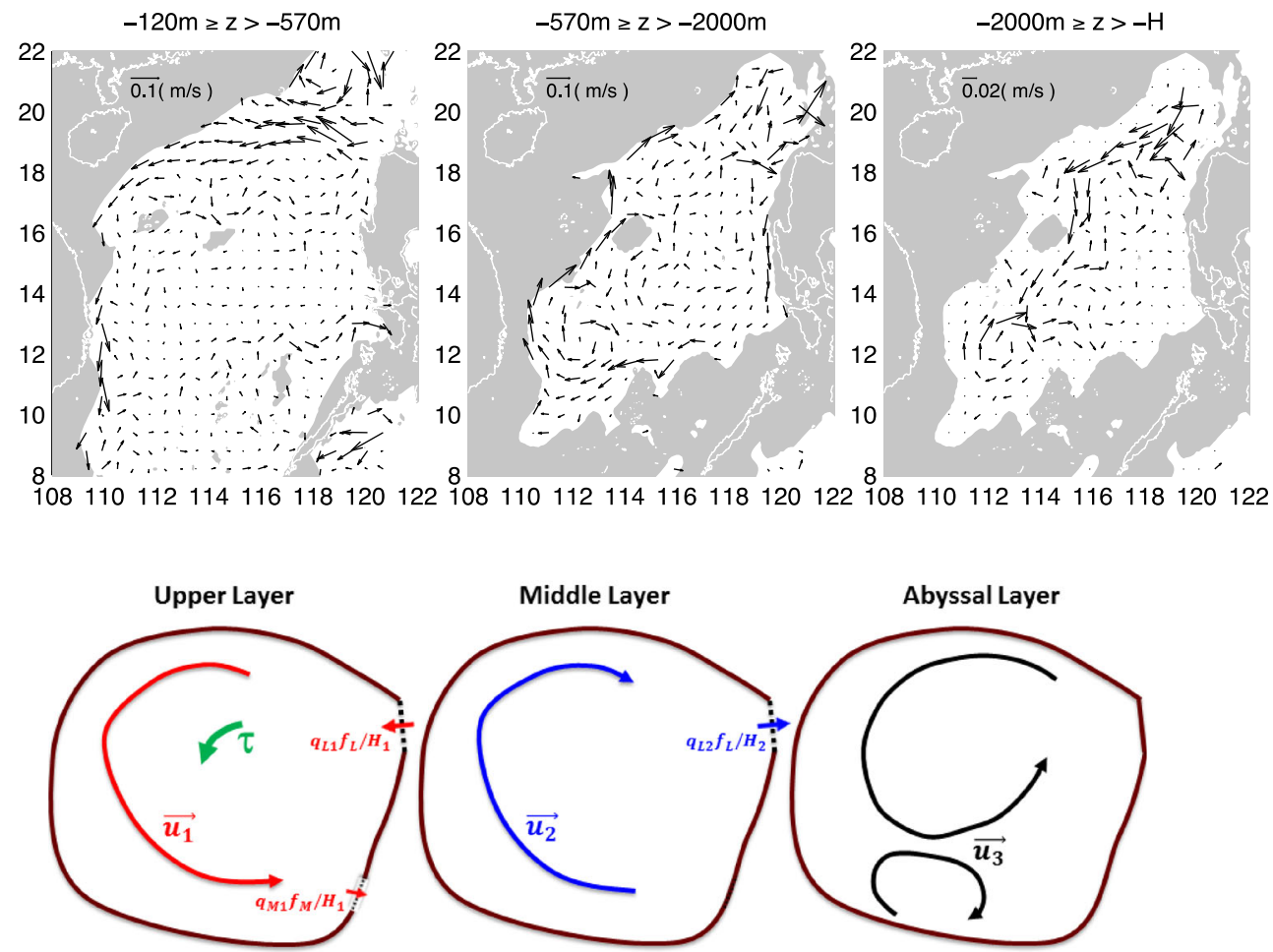
$\tau=$ kinematic interfacial stress, $r$ is the (constant) linear friction coefficient, $\zeta=\mathbf{k} . \nabla \times \mathbf{u}$ is the $z$-component (unit vector $\mathbf{k}$ ) of the relative vorticity, $Q$ represents a prescribed mass source concentrated in a small region (Stommel 1958), and $\kappa$ is the (constant) Newtonian cooling coefficient representing flowdependent vertical flux (Kawase 1987). Take the curl k. $\nabla \times$ of Eq. (6):

$\partial(f+\zeta) / \partial t+\nabla \cdot[\mathbf{u}(f+\zeta)]=\mathbf{k} . \nabla \times(\tau / H)-r \zeta$.

Integrate over the basin (Yang and Price 2000):

$\oint_{C}(\boldsymbol{u} \cdot \boldsymbol{n})(f+\zeta) \cdot d s=\oint_{C}\left(\frac{\boldsymbol{\tau}}{H}-r \boldsymbol{u}\right) \cdot \boldsymbol{l} d s$,

and use Eq. (5):

$\oint_{C} r \boldsymbol{u} . \boldsymbol{l} d s \approx \oint_{C}\left(\frac{\boldsymbol{\tau}}{H}\right) . \boldsymbol{l} d s^{-} \sum_{i=1}^{N} q_{i} f_{i} / H_{i}$

where $C$ is the bounding circuit (boundary) around the basin, and the integral is taken along the circuit, $\boldsymbol{n}$ and $\boldsymbol{l}$ are unit vectors normal and tangential to $C$, respectively, $\boldsymbol{n}$ is positive outward across $C$ and $\boldsymbol{l}$ is positive anticlockwise along $C, N$ is the number of openings around $C$ (i.e., straits), $q_{i}$ is the volume flux through the $i$ th opening and it is negative for influx into the basin, and $f_{i}$ and $H_{i}$ are the Coriolis and mean layer depth, respectively, at the $i$ th opening which is moreover assumed to be sufficiently narrow that $f_{i}$ can be taken to be constant across the opening.

\subsection{Upper layer}

This layer has two openings: one at Luzon with $q_{L 1} f_{L} / H_{1}<$ 0 (influx) and the other one at Mindoro Strait with $q_{M 1} f_{M} /$ $H_{1}>0$ (outflux). Here, subscripts $L$ and $M$ denote Luzon and Mindoro, respectively, and "1" denotes layer 1 or the upper layer. From the numerical model (Fig. 11, left), we find that $\left|q_{M 1}\right|<\left|q_{L 1}\right|$, and since $f_{M}<f_{L}$, influx of $P V$ into SCS exceeds outflux. The net contribution of $P V$ fluxes, $-\sum_{i=1}^{N} q_{i} f_{i} / H_{i}$, to the basin's circulation $\oint_{C} r u . l d s$ is therefore cyclonic. The upper layer is also acted on by Ekman pumping $\nabla \times \tau$ which is positive for SCS ( $\mathrm{Qu} 2000)$ contributing also to a cyclonic circulation. The resulting basin's circulation in the upper layer is therefore cyclonic, as sketched in the left lower panel of Fig. 11.

\subsection{Middle layer}

Here, the basin only has one opening in the Luzon Strait where numerical model shows an outflow, and therefore, the basin's circulation is anticyclonic (Fig. 11, middle).

\subsection{Abyssal (lower) layer}

Here the basin is closed, and the RHS term of Eq. (9) $=0$, hence $\oint_{C} r \boldsymbol{u} . \boldsymbol{l} d s=0$, and the circulation for the abyssal basin is zero. Therefore, anticyclonic circulation in one region must be compensated by cyclonic circulation somewhere else (Chang and Oey 2011). As described above, the Pac10 model shows deep eddying gyres of alternating signs: cyclonic in the north and anticyclonic in the south (Fig. 11, right panels).

\subsection{Connection with the Luzon Strait transport}

Qu et al. (2006b) show that the abyssal circulation of the SCS is driven by overflow of dense North Pacific water through the Luzon Strait according to the hydraulic control theory of Whitehead et al. (1974); this theory assumes deep flow overlaid by a motionless layer above. The estimated deep transport is approximately $-2.4 \mathrm{~Sv}$, as shown in the top panel of Fig. 12 . In the present study, modeled transport below $z=1,500 \mathrm{~m}$ across the Luzon Strait is $-3.4 \mathrm{~Sv}$; of this, $2.0 \mathrm{~Sv}$ is computed to upwell across $z=-2,000 \mathrm{~m}$ in the deep basin of SCS, which therefore represents the simulated deep overflow (Fig. 12, bottom panel), in excellent agreement with the observed estimate by $\mathrm{Qu}$ et al.

By mass conservation, the deep inflow of $-3.4 \mathrm{~Sv}$ (below $z=-1,500 \mathrm{~m}$ ) into the SCS induces a basin-wide upwelling into the middle layer. A portion of this upwelled water, $2.4 \mathrm{~Sv}$, flows out the Luzon Strait through the middle layer, since the middle layer is by definition below the sill depth of the Mindoro-Panay Strait. Therefore, $1 \mathrm{~Sv}$ upwells into the upper layer (Fig. 12). The middle layer is squashed consistent with the anticyclonic circulation (Fig. 11). The model shows cyclonic circulation in the abyssal layer consistent with upwelling in the northern portion of the SCS, and an anticyclonic circulation therefore exists in the southern SCS because the deep basin is closed as discussed above. Such cyclonic and anticyclonic circulations are also suggested in the model of Chao et al. (1996). By simulating tracer released in the abyssal, Chao et al. (1996) found localized upwelling west of the Luzon Strait and attributed it to upward entrainment associated with inflow of Pacific water at the sill depth of the Luzon Strait; see also Chen and Wang (1998). The upwelling is also seen in the present simulation (Exp.Pac10) across $z=-2,000 \mathrm{~m}$ (Fig. 13, upper panel), centered near $\left(120^{\circ} \mathrm{E}, 20^{\circ} \mathrm{N}\right)$, and the corresponding upward flux is around $0.2 \mathrm{~Sv}$. In Eq. (5), such a localized flux is represented by $Q$, rather than the Newtonian cooling term $-\kappa \eta$ which represents a basin-wide vertical flux. The reduced-gravity model of Chang and Oey (2011) is used to study the effects on deep circulation of this localized upwelling in conjunction with overflow through the Luzon Strait. The localized outflux is specified as a Gaussian: 

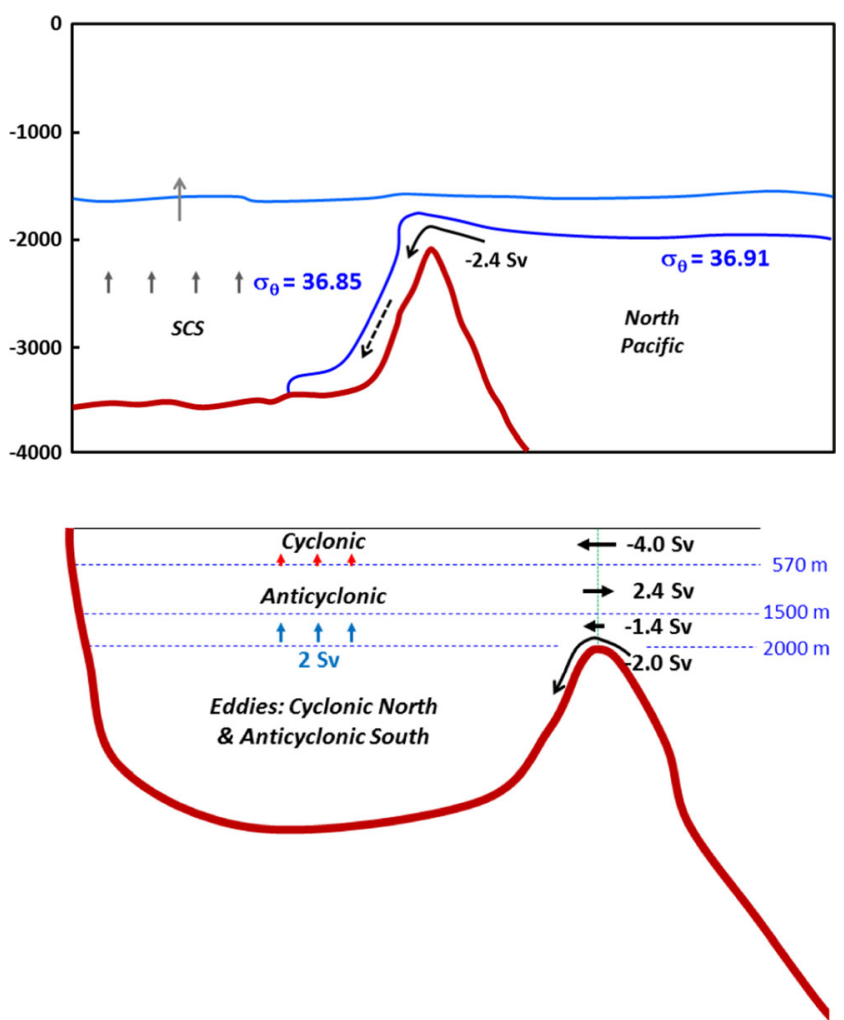

Fig. 12 Top panel: A sketch of dense-water overflow from the North Pacific Ocean into the South China Sea according to Qu et al. (2006b) who estimated -2.4-Sv-deep inflow according to the hydraulic control theory of Whitehead et al. (1974). Bottom panel: Modeled transport values across the Luzon Strait and the resulting upwelling in the deep basin of the South China Sea and the linkage with the horizontal circulation as discussed in text (see Figs. 11 and 13)

$Q=-0.2 \exp \left\{-\left[\left(x-x_{\mathrm{o}}\right)^{2}+\left(y-y_{\mathrm{o}}\right)^{2}\right] / R^{2}\right\} \quad$ in Sv,

where $x$ and $y$ are in degrees longitude and latitude, $R=0.6^{\circ}$, and the Gaussian is centered west of the Luzon Strait at $\left(x_{\mathrm{o}}, y_{\mathrm{o}}\right)=\left(120^{\circ} \mathrm{E}, 20^{\circ} \mathrm{N}\right)$. The overflow is specified as a volume flux $=-2.0 \mathrm{~Sv}$ (westward) at the Luzon Strait. Thus, a (small) fraction $(0.2 \mathrm{~Sv})$ of the overflow is upwelled near the Luzon Strait mimicking the results of Chao et al. (1996) and Exp.Pac10, but the remaining $(1.8 \mathrm{~Sv})$ is upwelled basin-wide through the Newtonian cooling term. The result below is relatively insensitive to the exact amount of the localized upwelling specified: $-0.05 \sim 0.30 \mathrm{~Sv}$. Parameters of the model are $g^{\prime}=0.01 \mathrm{~m} \mathrm{~s}^{-2}, \kappa=1 / 200$ day $^{-1}$, and $r=1 / 10$ day $^{-1}$ (c.f. Yang and Price 2000); the results are not sensitive to the precise values. The same bottom topography as in Exp.Pac10 is used. The model is integrated from the state of rest with the above forcing for 5 years; a steady state is reached in $\sim 3$ years.

The deep circulation (bottom panel of Fig. 13) is compared with that obtained from Exp.Pac10 (Fig. 11, top right panel). Along the northern edge of SCS, the reduced-gravity simulation shows a northeastward flow due to the nature of the forcing in the simple model (Yang and Price 2000); the eastward flow in the Exp.Pac10 is very weak. Apart from this difference, the simple model captures well the general features of the abyssal circulation seen in Exp.Pac10. A western boundary current exists in the northern SCS; it flows westsouthwestward and then around the eastern side of a deep seamount (near $114^{\circ} \mathrm{E}, 16^{\circ} \mathrm{N}$ ) in the west, as seen also in Fig. 11. In the southwestern basin, an anticyclonic circulation is seen, as is also found for Exp.Pac10. The anticyclone becomes weak if $Q=0$ (not shown), suggesting the importance of forcing on the abyssal circulation by upwelling west of the Luzon Strait as the Pacific water overflows into the SCS.

Cyclonic circulation in the northern part of the SCS was inferred by Wang et al. (2011) based on $T$ and $S$ data. Near the southwestern corner of the SCS, however, they found another cyclonic circulation. Lan et al. (2013) proposed a basin-scale cyclonic circulation using the Hybrid Coordinate Ocean Model. The authors propose based on Eq. (9) $(\tau=0)$ that positive PV induced by the inflow $(\boldsymbol{u} . \boldsymbol{n}<0)$ from Luzon Strait was balanced by the PV dissipation along the boundary. As in the present model, their model SCS is closed below 2,000 m, and they applied Eq. (9) assuming a sill depth of 2,400 m. In contrast to Chao et al. (1996) and Exp.Pac10, anticyclone was not observed. A long-term observation of the deep SCS circulation is required to clarify the circulation pattern in the southwestern SCS.

\section{Conclusions}

This study has achieved three goals. First, a LETKF dataassimilation scheme was successfully implemented into an ocean prediction system of the western North Pacific Ocean. The results are compared against satellite and Argo float data and also against estimates based on a simpler OI assimilation scheme, for the test period from January 20 to April 3, 2012. When compared against the OI scheme, the LETKF scheme shows generally improved solutions over the modeled region of the western North Pacific. A comparison of the modeled transports through the Luzon Strait (and at other sections) against observed transports taken from the literature has been carried out. The second goal that we have accomplished is that the analyzed Luzon Strait transports from both OI and LETKF show a three-layer structure: inflow (into SCS) in the upper layer, outflow in the middle layer (defined as 500-1,500 m), and inflow in the lower layer. The three-layer structure and transports agree well with observed transport estimates, except in one case when there was only a two-layer structure when a mesoscale eddy was present in the strait during the field program. A review of the literature indicates that this is the first time that the observed three-layer transport structure in the Luzon Strait has been successfully simulated in a model.

The three-layer transport structure in the Luzon Strait imposes strong dynamical constraints on the possible time-mean 
Fig. 13 SCS circulation below $z=-2,000 \mathrm{~m}$ calculated using a reduced-gravity model with $g^{\prime}=$ $0.01 \mathrm{~m} \mathrm{~s}^{-2}, \kappa=1 / 200 \mathrm{day}^{-1}$, and $r=1 / 10$ day $^{-1}$. Inflow $=-2.0 \mathrm{~Sv}$ is specified across the Luzon Strait to simulate deep overflow, and a Gaussian $Q=-0.2 \mathrm{~Sv}$ with radius $\approx 60 \mathrm{~km}$ centered at $120^{\circ} \mathrm{E}, 20^{\circ} \mathrm{N}$ is specified to simulate upwelling west of the Luzon Strait seen in the Exp.Pac10 (top inset: 18-year mean $w, \mathrm{~m} \mathrm{day}^{-1}$ ). Vectors are truncated at $0.01 \mathrm{~m} \mathrm{~s}^{-1}$ to show the anticyclone in the south. Topography is the same as that used in Exp.Pac10 based on the 2min Etopot2 (http://www.ngdc. noaa.gov/mgg/global/etopo2. html)
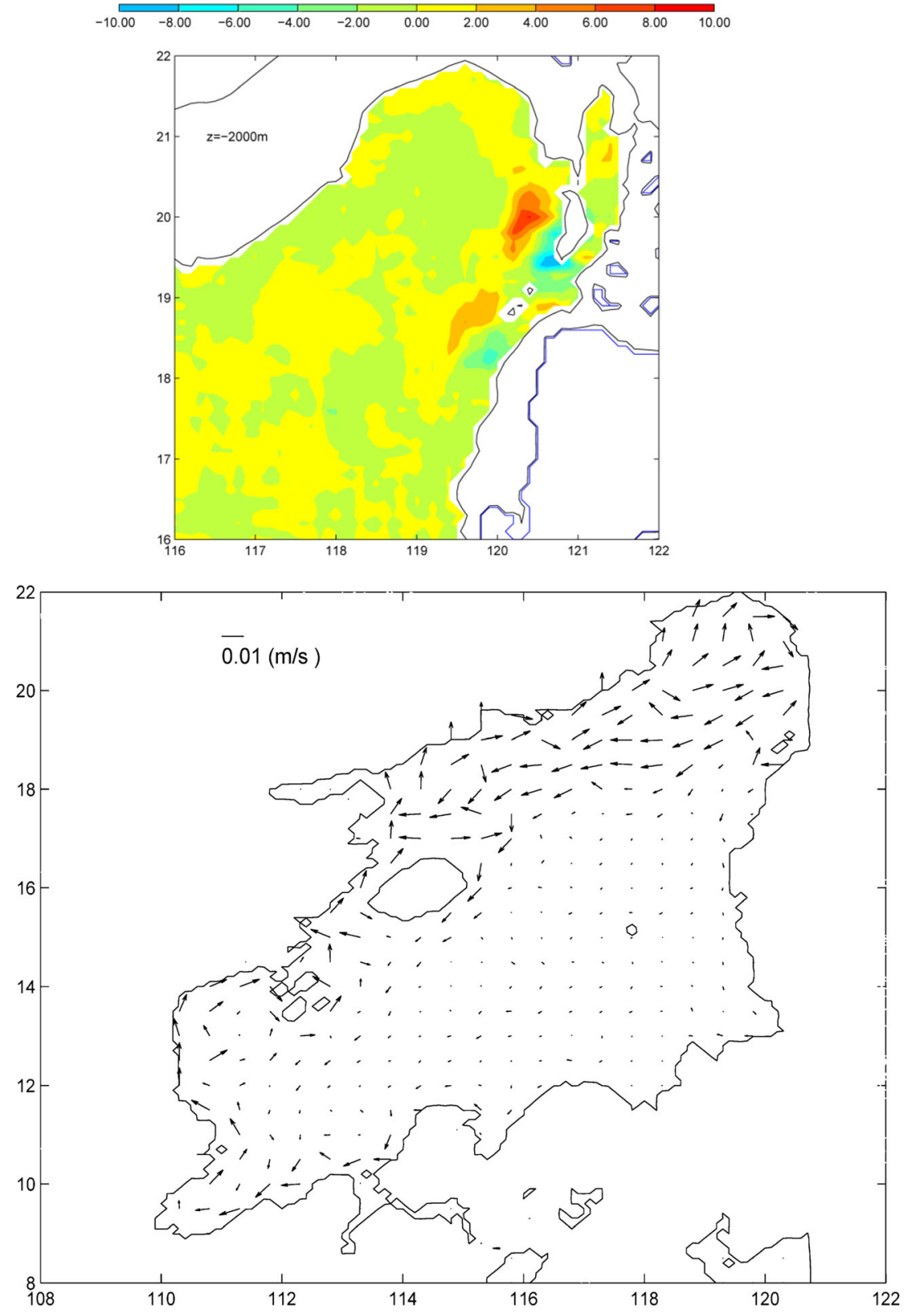

basin-scale circulations in the SCS. The third goal is therefore to find and explain such solutions in the model. In order to do this, instead of the regional western North Pacific model with data assimilations, we resort to the long-term integration results of a basin-scale model of the entire North Pacific Ocean forced by a blended satellite and reanalysis wind product. Eighteen-year mean transports in the Luzon Strait again show a robust three-layer structure which confirms LETKF and OI analyses. We deduce by conservations of mass and potential vorticity that the mean circulations in the SCS consist also of three layers. The upper layer $(-120 \mathrm{~m}>z>-570 \mathrm{~m})$ circulation is cyclonic driven by Ekman pumping by the wind stress curl and by inflow through the Luzon Strait. The middle layer $(-570 \sim-2,000 \mathrm{~m})$ is anticyclonic due to outflow transport through the Luzon Strait. The abyssal basin $(<-2,000 \mathrm{~m})$ is driven by deep overflow from the Luzon Strait, which produces localized upwelling; the resulting deep circulation is cyclonic in the northern portion of the SCS, but it is anticyclonic in the southern portion.

Acknowledgments We are grateful to the three reviewers and the editor for their comments and suggestions that improved the manuscript. We thank Y.-L. Chang, Y.-C. Lin, and M.-C. Chang of the ATOP Group for their assistance in running the mpiPOM. The supports for FHX from the National Basic Research Program of China (973 Program, Grant No. 2013CB956603) and from the start-up funds of the Tsinghua University are acknowledged. LYO is grateful for the award from the Taiwan's Foundation for the Advancement of Outstanding Scholarship and acknowledges partial supports from the National Science Council and the National Central University. 
Open Access This article is distributed under the terms of the Creative Commons Attribution License which permits any use, distribution, and reproduction in any medium, provided the original author(s) and the source are credited.

\section{References}

Atlas R, Hoffman RN, Ardizzone J, Leidner M, Jusem JC (2009) Development of a new cross-calibrated, multi-platform (CCMP) ocean surface wind product. AMS 13th Conference on Integrated Observing and Assimilation Systems for Atmosphere, Oceans, and Land Surface (IOAS-AOLS)

Berntsen J, Oey LY (2010) Estimation of the internal pressure gradient in sigma-coordinate ocean models: comparison of second-, fourth-, and sixth-order schemes. Ocean Dyn 60:317-330

Blumberg AF, Mellor GL (1987) A description of a three-dimensional coastal ocean circulation model. In: Heap N (ed) Three-dimensional coastal ocean models, coastal estuarine stud, vol 4. AGU, Washington, DC, pp 1-16

Chang YL, Oey LY (2011) Loop Current cycle: coupled response of the Loop Current with deep flows. J Phys Oceanogr 41(3): 458-471

Chang YL, Oey LY (2012) The Philippines-Taiwan oscillation: monsoonlike interannual oscillation of the subtropical-tropical western North Pacific wind system and its impact on the ocean. J Climate 25:1597-1618. doi:10.1175/JCLI-D-11-00158.1

Chang Y, Oey L (2013) Loop Current growth and eddy shedding using models and observations Part 1: numerical process experiments and satellite altimetry data. J Phys Oceanogr 43:669-689

Chang Y-L, Oey L-Y (2014) Instability of the North Pacific subtropical countercurrent. J Phys Oceanogr 44:818-833

Chao S-Y, Shaw P-T, Wu SY (1996) Deep water ventilation in the South China Sea. Deep Sea Res I Oceanogr Res Pap 43(4):445-466. doi: 10.1016/0967-0637(96)00025-8, ISSN 0967-0637

Chen C-T (2005) Tracing tropical and intermediate waters from the South China Sea to the Okinawa Trough and beyond. J Geophys Res 110, C05012. doi:10.1029/2004JC002494

Chen C-T, Huang MH (1996) A mid-depth front separating the South China Sea water and the Philippine Sea water. J Oceanogr 52:17-25. doi:10.1007/BF02236530

Chen C-T, Wang S-L (1998) Influence of the intermediate water in the western Okinawa Trough by the outflow from the South China Sea. J Geophys Res 103:12,683-12,688

Chu PC, Edmons NL, Fan CW (1999) Dynamical mechanisms for the South China Sea seasonal circulation and thermohaline variabilities. J Phys Oceanogr 29:2971-2989

Gan J, Li H, Curchitser EN, Haidvogel DB (2006) Modeling South China Sea circulation: response to seasonal forcing regimes. J Geophys Res 111, C06034. doi:10.1029/2005JC003298

Gordon AL, Huber BA, Metzger EJ, Susanto RD, Hurlburt HE, Adi TR (2012) South China Sea throughflow impact on the Indonesian throughflow. Geophys Res Lett 39, L11602. doi:10.1029/ 2012GL052021

Guo X, Miyazawa Y, Yamagata T (2006) The Kuroshio onshore intrusion along the shelf break of the East China Sea: the origin of the Tsushima warm current. J Phys Oceanogr 36:2205-2231. doi:10. 1175/JPO 2976.1

Hsin Y-C, Wu C-R, Chao S-Y (2012) An updated examination of the Luzon Strait transport. J Geophys Res 117, C03022. doi:10.1029/ 2011JC007714

Hu JY, Kawamura H, Hong H, Qi YQ (2000) A review on the currents in the South China Sea: seasonal circulation, South China Sea warm current and Kuroshio intrusion. J Oceanogr 56:607-624
Hunt BR, Kostelich EJ, Szunyogh I (2007) Efficient data assimilation for spatiotemporal chaos: a local ensemble transform Kalman filter. Phys D 230:112-126

Isobe A (2008) Recent advances in ocean-circulation re- search on the Yellow Sea and East China Sea shelves. J Oceanogr 64:569-584. doi:10.1007/s10872-008-0048-7

Johns WE, Lee TN, Zhang D, Zantopp R, Liu CT, Yang Y (2001) The Kuroshio east of Taiwan: moored transport observations from the WOCE PCM-1 array. J Phys Oceanogr 31:1031-1053

Jordi A, Wang D-P (2012) sbPOM: a parallel implementation of Princeton Ocean Model. Environ Model Softw 38:59-61. doi:10. 1016/j.envsoft.2012.05.013, December 2012

Kawase M (1987) Establishment of deep ocean circulation driven by deep-water production. J Phys Oceanogr 17:2294-2317

Lan J, Zhang N, Wang Y (2013) On the dynamics of the South China Sea deep circulation. J Geophys Res Oceans 118:1206-1210. doi:10. 1002/jgrc.20104

Liao G, Yuan Y, Xu X (2008) Three dimensional diagnostic study of the circulation in the South China Sea during winter 1998. J Oceanogr 64:803-814

Lin SF, Tang TY, Jan S, Chen CJ (2005) Taiwan Strait current in winter. Cont Shelf Res 25(9):1023-1042

Lin X, Oey L-Y, Wang D-P (2007) Altimetry and drifter assimilations of Loop Current and eddies. JGR 112:C05046

Liu JY (2013) Status of marine biodiversity of the China seas. PLoS One 8(1):e50719. doi:10.1371/journal.pone.0050719

Liu KK, Tang TY, Gong GC, Chen LY, Shiah FK (2000) Cross-shelf and along-shelf nutrient fluxes derived from flow fields and chemical hydrography observed in the southern East China Sea off northern Taiwan. Cont Shelf Res 20:493-523. doi:10.1016/S0 278-4343(99) 00083-7

Mellor GL, Blumberg AF (1985) Modeling vertical and horizontal diffusivities with the Sigma Coordinate system. Mon Weather Rev 113: 1379-1383

Metzger EJ, Hurlburt HE (1996) Coupled dynamics of the South China Sea, the Sulu Sea, and the Pacific Ocean. J Geophys Res Oceans 101(C5):12,331-12,352

Metzger EJ, Hurlburt H (2001) The importance of high horizontal resolution and accurate coastline geometry in modeling South China Sea inflow. Geophys Res Lett 28(6):1059-1062

Miyazawa Y, Miyama T, Varlamov SM, Guo X, Waseda T (2012) Open and coastal seas interactions south of Japan represented by an ensemble Kalman Filter. Ocean Dyn. doi:10.1007/s10236-0110516-2

Miyoshi T, Sato Y, Kadowaki T (2010) Ensemble Kalman filter and 4DVar intercomparison with the Japanese operational global analysis and prediction system. Mon Wea Rev 138:2846-2866

Oey LY, Chen P (1992a) A model simulation of circulation in the northeast Atlantic shelves and seas. J Geophys Res 97:2008720115. doi:10.1029/92JC01990

Oey LY, Chen P (1992b) A nested-grid ocean model: with application to the simulation of meanders and eddies in the Norwegian Coastal Current. J Geophys Res 97:20063-20086. doi:10.1029/ 92JC01991

Oey L-Y, Ezer T, Forristall G, Cooper C, DiMarco S, Fan S (2005) An exercise in forecasting Loop Current and eddy frontal positions in the Gulf of Mexico. Geophys Res Let 32:L12611, 2005GL023253

Oey LY, Chang YL, Lin YC et al (2013) ATOP-the Advanced Taiwan Ocean Prediction System based on the mpiPOM. Part 1: model descriptions, analyses and results. Terr Atmos Ocean Sci 2013:24

Oey L-Y, Chang Y-L, Lin Y-C, Chang M-C, Varlamov S, Miyazawa Y (2014) Cross flows in the Taiwan Strait in Winter*. J Phys Oceanogr 44:801-817

Ott E et al (2004) A local ensemble Kalman filter for atmospheric data assimilation. Tellus 56A:415-428 
Qu T (2000) Upper-layer circulation in the South China Sea. J Phys Oceanogr 30:1450-1460

Qu T, Kim YY, Yaremchuk M, Tozuka T, Ishida A, Yamagata T (2004) Can Luzon Strait transport play a role in conveying the impact of ENSO to the South China Sea?*. J Climate 17:3644-3657

Qu T, Du Y, Sasaki H (2006a) South China Sea throughflow: a heat and freshwater conveyor. Geophys Res Lett 33:23

Qu T, Girton JB, Whitehead JA (2006b) Deepwater overflow through Luzon Strait. J Geophys Res 111, C01002. doi:10.1029/ 2005JC003139

Qu T, Song T, Yamagata T (2009) An introduction to the South China Sea throughflow: its dynamics, variability, and implication for climate. Dyn Atmos Oceans 47:3-14

Rio MH, Guinehut S, Larnicol G (2011) New CNES-CLS09 global mean dynamic topography computed from the combination of GRACE data, altimetry, and in situ measurements. J Geophys Res 116, C07018. doi:10.1029/2010JC006505

Rong Z, Liu Y, Zong H, Cheng Y (2007) Interannual sea level variability in the South China Sea and its response to ENSO. Glob Planet Chang 55:257-272. doi:10.1016/j.gloplacha.2006.08.001

Shaw PT, Chao SY (1994) Surface circulation in South China Sea. Deep Sea Res Part I 40:1663-1683

Sheu W-J, Wu C-R, Oey L-Y (2010) Blocking and westward passage of eddies in the Luzon Strait. Deep Sea Res II Top Stud Oceanogr 57(19-20):1783-1791

Song YT (2006) Estimation of interbasin transport using ocean bottom pressure: theory and model for Asian marginal seas. J Geophys Res 111:C11S19. doi:10.1029/2005JC003189

Sprintall J, Gordon A, Flament P, Villanoy C (2012) Observations of exchange between the South China Sea and the Sulu Sea. J Geophys Res 117, C05036. doi:10.1029/2011JC007610

Stommel H (1958) The abyssal circulation. Letter to the editors. Deep Sea Res 5:80-82

Szunoygh I, Kostelich EJ, Gyarmati G, Patil DJ, Kalnay E, Ott E, Yorke JA (2005) Assessing a local ensemble Kalman filter: perfect model experiments with the National Centers for Environmental Prediction global model. Tellus 57A:528-545

Tian J, Yang Q, Liang X, Xie L, Hu D, Wang F, Qu T (2006) Observation of Luzon Strait transport. Geophys Res Lett 33, L19607. doi:10. 1029/2006GL026272

Wang C, Wang W, Wang D, Wang Q (2006) Interannual variability of the South China Sea associated with El Niño. J Geophys Res 111:C3

Wang G, Xie SP, Qu T, Huang RX (2011) Deep South China Sea circulation. Geophys Res Lett 38, L05601. doi:10.1029/2010GL046626

Whitehead JA, Leetmaa A, Knox RA (1974) Rotating hydraulics of strait and sill flows. Geophys Fluid Dyn 6:101-125
Willmott CJ (1981) On the validation of models. Phys Geogr 2: $184-194$

Wyrtki K (1961) Physical oceanography of the Southeast Asian waters. Scripps Inst Oceanogr Univ Calif, La Jolla 2:195

Xie S, Xie Q, Wang D, Liu WT (2003) Summer upwelling in the South China Sea and its role in regional climate variations. J Geophys Res 108(C8):3261. doi:10.1029/2003JC001867

Xu F-H, Oey L-Y, Miyazawa Y, Hamilton P (2013a) Hindcasts and forecasts of loop current and eddies in the Gulf of Mexico using local ensemble transform Kalman filter and optimum-interpolation assimilation schemes. Ocean Model 69:22-38. doi:10.1016/j.ocemod.2013.05.002

Xu F, Chang Y, Oey L, Hamilton P (2013b) Loop current growth and eddy shedding using models and observations: analyses of the July 2011 eddy-shedding event. J Phys Oceanogr 43:1015-1027

Xue H, Chai F, Pettigrew N, Xu D, Shi M, Xu J (2004) Kuroshio intrusion and the circulation in the South China Sea. J Geophys Res 109, C02017. doi:10.1029/2002JC001724

Yang J, Price JF (2000) Water-mass formation and potential vorticity balance in an abyssal ocean circulation. J Mar Res 58(5):789-808

Yang Q, Tian J, Zhao W (2010) Observation of Luzon Strait transport in summer 2007. Deep Sea Res Part I 57:670-676

Yaremchuk M, Qu T (2004) Seasonal variability of the large-scale currents near the coast of the Philippines. J Phys Oceanogr 34:844 855

Yin XQ, Oey LY (2007) Bred-ensemble ocean forecast of loop current and rings. Ocean Model 17:300-326

Yuan Y, Liao G, Yang C (2008a) The Kuroshio near the Luzon Strait and circulation in the northern South China Sea during August and September 1994. J Oceanogr 64:777-788

Yuan Y, Liao G, Guan W, Wang H, Lou R, Chen H (2008b) The circulation in the upper and middle layers of the Luzon Strait during spring 2002. J Geophys Res 113:C06004

Yuan Y, Liao G, Yang C (2009) A diagnostic calculation of the circulation in the upper and middle layers of the Luzon Strait and the northern South China Sea during March 1992. Dyn Atmos Oceans 47:86113

Zhang Z, Zhao W, Liu Q (2010) Subseasonal variability of Luzon Strait transport in a high resolution global model. Acta Oceanol Sin 29:9-17

Zhang Z, Zhao W, Tian J, Liang X (2013) A mesoscale eddy pair southwest of Taiwan and its influence on deep circulation. J Geophys Res Oceans. doi:10.1002/2013JC008994

Zhou H, Nan F, Shi M, Zhou L, Guo P (2009) Characteristics of water exchange in the Luzon Strait during September 2006. Chin J Oceanology Limnol 27(3):650-665 